\title{
Capacity, Willingness, and Sovereign Default Risk: Reassuring the Market in Times of Crisis
}

\author{
Forthcoming in JCMS: Journal of Common Market Studies
}

\author{
Jørgen Bølstad* \\ Christoph Elhardt ${ }^{\dagger}$
}

\begin{abstract}
Preserving the trust of bond markets is crucial for the world's many indebted countries, but it is still unclear when and how national or international actors can contribute to this goal. We present a set of arguments addressing this question and test them on the case of the Eurozone debt crisis. Distinguishing between actors' capacity and willingness to avoid defaults, we argue that the crisis was marked by a lack of capacity at the national level, and limited or uncertain willingness at the European level. Accordingly, we find that European-level efforts to reassure markets had considerably stronger effects than similar efforts at the national level. Furthermore, national efforts appear to have mattered the least in countries with the least capacity. These findings are based on a comprehensive new dataset of political events and relevant news, and they hold across a number of robustness checks and placebo tests.
\end{abstract}

Correspondence:

Jørgen Bølstad

ARENA Centre for European Studies

University of Oslo

PO Box 1143 Blindern

Oslo, Norway

E-mail: jorgen.bolstad@arena.uio.no

Acknowledgements:

For their helpful comments at various stages of the project, we would like to thank Michael Bechtel, Loriana Crasnic, Steve Heinke, Iain McMenamin, Frank Schimmelfennig, Stefanie Walter, Andreas Wenger, and Thomas Winzen.

\footnotetext{
${ }^{*}$ University of Oslo

${ }^{\dagger}$ ETH Zurich
} 
In a world where most governments are heavily indebted, preserving the trust of bond markets is a key task for policy-makers. Failing this task and losing investors' trust can have dramatic consequences, even pushing otherwise solvent states to the brink of default. Yet, the role of politics in determining default risk has received little attention in the academic literature, especially when it comes to advanced economies. Furthermore, most studies on sovereign debt focus exclusively on national factors, and leave aside the role of external actors, such as other states, the International Monetary Fund (IMF), or the European Union (EU). Thus, how and under what conditions national or international actors can reassure investors that states' financial obligations will be honored is still an open question.

The European debt crisis is particularly well-suited for studying this topic. Compared to other sovereign debtors, the members of the Eurozone (EMU) are especially weak, as they have abandoned their national currencies and lost the ability to conduct their own monetary policy: Economic imbalances within the monetary union can no longer be solved through adjustments in exchange rates, and national central banks can no longer act as lenders of last resort if their governments face liquidity problems (De Grauwe and Ji, 2012). This crucial function now primarily lies with the EU and the European Central Bank (ECB), and EMU member states are therefore thought to be more vulnerable to sudden stops in debt financing than countries possessing their own currencies (De Grauwe and Ji, 2013; De Haan et al., 2014). Debt issued by governments within the Eurozone thus appears particularly risky, and during the crisis, the task of preserving or regaining investors' trust became paramount. The crisis thus offers an exceptional amount of attempts to reassure the market and reduce the cost of borrowing. ${ }^{1}$

This study develops and tests a set of theoretical arguments regarding when such efforts will be effective. In particular, we argue that investors distinguish between actors' capacity and willingness to avoid defaults, and that signals of willingness lose their relevance as an actor's capacity declines. We further argue that the European debt crisis was marked by considerable skepticism regarding the capacities of Greece, Ireland, Italy, Portugal and Spain (GIIPS). In contrast, we argue that the capacities of the ECB and the EU-level actors were seen as high, while their willingness was surrounded by great uncertainty. This leads to the expectation that key political signals at the European level would matter more than those at the national level. To test our arguments, we have collected a comprehensive new dataset of relevant events during the crisis. Specifically, we analyze how the spreads on sovereign bonds react to crisis-measures by the ECB and the EU (i.e. the European Council, ECOFIN, and the Euro-Group), as well as to national reforms and other political events in the GIIPS-countries. The results, which we discuss

\footnotetext{
${ }^{1}$ While our analysis focuses on the secondary debt market, it is still highly relevant to states' debt financing, as primary market auctions tend to stay close to the yields in the secondary market.
} 
in more detail below, are generally in line with our expectations.

\section{Capacity and Willingness to Avoid Defaults}

A key focus in the literature on sovereign debt has been on national debt servicing capacity - often also referred to as fiscal space. According to Heller (2005), fiscal space is the "room in a government's budget that allows it to provide resources for a desired purpose without jeopardizing the sustainability of its financial position or the stability of the economy". Alternatively, Ghosh et al. $(2013,133)$ define a "debt limit" - beyond which "debt dynamics become explosive and the government becomes unable to fully meet its obligations" - and they proceed to define fiscal space as the "distance between current (or projected) debt levels and this debt limit". In practice, however, fiscal space is normally captured by narrower proxies, such as public deficit- or debt-to-GDP ratios. Recently, more refined definitions have also been proposed - in particular one defining "a de facto fiscal space as being inversely related to the tax-years it would take to repay the public debt" (Aizenman and Jinjarak, 2010). Stock and flow measures of this concept have been operationalized as "outstanding government debt and government deficits, relative to the de facto tax base" (Aizenman et al., 2013), and we employ these measures below.

While many studies have focused solely on capacity and debt sustainability, a few have also noted that the repayment of public debt partly depends on political willingness. For instance, Tomz $(2007,15)$ notes that "[w] hen a government pleads poverty in negotiations with international creditors, this almost never implies that the government is penniless", but rather "signals a lack of political will to elevate the foreign debt over other concerns". This illustrates how default risk is not simply a question of economics, but may also crucially depend on political factors. Nevertheless, studies of political willingness are relatively rare, and say little about when governments might be able to reassure markets of their willingness to honor their debts. One line of research has treated willingness as a government's purely rational analysis of economic costs and benefits, and developed formal models of the calculations involved (Eaton and Gersovitz, 1981; Eaton et al., 1986). Another line of research has had a more empirical focus, but relied on fairly crude proxies of willingness that tend to show little variation over time (e.g. Breen and McMenamin, 2013; Cantor and Packer, 1996; Stasavage, 2011). A key aim of the present study is therefore to examine the effects of more specific signals of political willingness in times of crisis, and theorize when these should be effective. ${ }^{2}$

\footnotetext{
${ }^{2}$ By doing so, our study also adds to a growing number of studies on the effects of news on financial markets in times of crisis (e.g. Mink and de Haan, 2013; Beetsma et al., 2013). While such studies mainly differentiate between good and bad news, our more fine-grained data allows us to show that investors indeed do distinguish between news about what policy makers say and do and more general news about
} 
While the existing literature overwhelmingly focuses on national sources of default risk, we argue that the role of international actors also should be accounted for, and that the distinction between capacity and willingness is equally important in this regard. A country's probability of default is therefore best understood as a function of several more specific probabilities (as we discuss in detail in the appendix). In line with the existing literature, we argue investors have to assess the probability that countries are willing and able to service their debt in full (without external support), and we refer to the subjective assessment of this probability as primary trust. ${ }^{3}$ However, investors also have to assess the probability that a country will be rescued by external actors in case it is no longer able to service its liabilities on its own, which we refer to as secondary trust.

We further argue that investors distinguish between actors' capacity and willingness to avoid defaults. Such considerations are, for instance, evident in the methodologies of the major rating agencies, who assess not only countries' debt servicing capacities, but also political risk - even if the latter is largely assessed qualitatively or by way of proxies. We define actors' capacity as their scope for avoiding default, and we consider this scope at any particular time point as given, representing factors that lie outside of the actors' control. We further define actors' willingness to avoid default as their intended use of their capacity - whether they will indeed avoid defaults if they have the capacity to do so. We argue that willingness (or the lack of it) can be signaled through relevant statements and decisions, and the focus of this study is the question of when such signals are effective at shaping investors' trust. We argue not only that investors assess both capacity and willingness, but also that sufficient capacity and willingness are considered to be individually necessary and jointly sufficient conditions for successful efforts to avoid default. A key implication of our model (which is detailed in the appendix) is that the effect of signals regarding an actor's willingness is conditioned by this actor's capacity. As an actor's capacity declines, the relevance of this actor's willingness (and signals regarding this willingness) is also diminished.

\section{The Eurozone Crisis}

Applying this argument to the Eurozone crisis requires consideration of how the relevant actors score in terms of perceived capacity and willingness. Starting with the capacities of the GIIPS countries, it is worth noting that even before the crisis, several these countries (i.e. Greece, Italy, and Portugal) "had more limited fiscal space ... than other high-

\footnotetext{
the political and economic situation of a country.

${ }^{3}$ Using the term trust is in line with a number of earlier studies (e.g. De Grauwe and Ji, 2013; Mosley, 2004). We use the term in a rationalist sense, where investors' expected gains depends on other actors and trust refers to the subjectively assessed probability that these act in accordance with investors' interests.
} 
income groups" - but they also faced lower yields than their fundamentals would predict (Aizenman et al., 2013, 44). Once the crisis struck, the situation for the GIIPS countries got significantly worse, and their capacity to service their debt was widely questioned (Beirne and Fratzscher, 2013; Bernoth and Erdogan, 2012; De Haan et al., 2014; Ghosh et al., 2013; Goldbach and Fahrholz, 2011). ${ }^{4}$ In the next section, we provide data on the countries' fiscal space and discuss the differences among them in this regard. For now, however, our main argument is that their capacities were generally seen as low, thus undermining investors' primary trust.

In contrast, the willingness of the GIIPS countries caused investors less concern. This observation is in line with the existing literature, which suggests that governments generally should have a rather high willingness to avoid defaults. Ghosh et al. (2013, 113) state, for example, that "[c]onsistent with empirical evidence ... we posit that governments typically act responsibly, raising the primary balance in response to rising public debt". Such behavior is normally rational, as defaults are costly, not least to the domestic investors and banks, and ultimately to the whole economy (Borensztein and Panizza, 2009; Hatchondo et al., 2007; Mendoza and Yue, 2012; Panizza et al., 2009). Unordered defaults may also require closing a primary deficit immediately, which in the case of Greece, for example, could have necessitated leaving the Euro according to some observers. Thus, as long as governments can avoid defaulting, we generally expect that they will try to do so. Yet, what ultimately matters is a country's willingness in a broader sense, as governments need the consent of their electorates, and these may be highly opposed to reforms improving the primary balance. Domestic political constraints can thus give rise to considerable uncertainty about the national willingness to avoid defaults, even if defaulting is generally unattractive.

At the European level, this picture is reversed. Here, we focus on the coordinated actions of the Eurozone countries (which we refer to as the EU), as well as actions by the ECB. At this level, capacity refers to the actors' ability to avoid defaults in particular Eurozone countries. Given the size of the non-GIIPS Eurozone economies, their governments have considerable capacity to bail out the GIIPS countries (although this capacity is somewhat more questionable for the largest debtors, as we discuss further below). Furthermore, the ECB is generally thought to have extensive capacity to bail out any country, acting as a lender of last resort, should it choose to do so. ${ }^{5}$ In sum, we argue that the actors at the European level are seen as having considerable capacity to

\footnotetext{
${ }^{4}$ The case of Ireland is particular in the sense that its public finances were sound before the crisis and deteriorated as the government took on the obligations of the troubled banking sector.

${ }^{5}$ See, for instance, De Grauwe (2013). Note that we consider questions regarding formal constraints on the ECB's capacity as reflecting European-level willingness avoid defaults, and thus argue that the capacity of the ECB as a central bank is considerable, provided there is willingness to use it.
} 
avoid defaults in Eurozone countries.

During the crisis, the key question regarding the European level was rather whether sufficient willingness indeed was present. The Maastricht treaty explicitly ruled out bailouts, yet the markets largely seemed to ignore this clause. Before the onset of the debt crisis in October 2009, sovereign bond yields in the Eurozone were converging, despite the relatively unfavorable fundamentals of the GIIPS countries. In other words, investors apparently saw EMU as reducing the risk of bonds in the periphery, considering the Eurozone countries jointly responsible for bonds issued within the union (Ghosh et al., 2013; Goldbach and Fahrholz, 2011). Once doubts were raised about the capacities of the GIIPS countries to service their debt, the issue of European willingness to bail them out gained salience. After the negotiations on Greece's rescue package dragged on for several months with Germany insisting on strict conditionality, markets began to realize that European willingness could be much lower than earlier market prices would imply. During this early phase of the crisis, many officials (not least German ones) were voicing their opinions against bail-outs, and we argue that European willingness at this time was seen as low (or uncertain at best), thus undermining investors' secondary trust (see, for instance, Paterson, 2011; Bechtel et al., 2014).

\section{Further Considerations and Expectations}

The arguments above, which are in line with standard accounts of the crisis, have several implications for the effects we would expect of relevant signals during the crisis. However, before we develop these implications into hypotheses, a few additional considerations require attention. First, we argue it is important to distinguish between statements and decisions, and thus also to consider when markets should react to either type of signal. In line with Bølstad and Elhardt (2015), we argue that statements only carry useful information insofar as they are credible and allow the anticipation of later decisions (see also Bechtel and Schneider, 2010). Political actors generally lack such credibility, as they have strategic incentives to please both markets and domestic constituencies. Under such conditions, statements carry little information, and investors are likely to await actual decisions. In other words, both for national governments and the EU, we would expect decisions to have greater effects than statements. In contrast, the technocratic ECB is far more credible, and therefore able to use statements as a tool for signaling its intentions - as in the case of forward guidance. The ECB's statements have thus been found to matter more than its decisions (Bølstad and Elhardt, 2015). Accordingly, we refer to key signals for the different actors: Decisions for political actors (both at the national and European level), and statements for the ECB.

As we discuss further in the analysis section and the appendix, we also distinguish between positive and negative signals. At the national level, we generally consider state- 
Table 1: Average GIIPS fiscal spaces in terms of tax-years, 2009-2012.

\begin{tabular}{lccccc}
\hline & Greece & Ireland & Italy & Portugal & Spain \\
\hline Fiscal balance to tax base (FB) & -0.27 & -0.45 & -0.08 & -0.19 & -0.27 \\
Public debt to tax base (PD) & 3.77 & 1.99 & 2.06 & 2.32 & 0.99 \\
FB-ratio times PD-ratio & -0.99 & -0.88 & -0.17 & -0.43 & -0.26 \\
\hline
\end{tabular}

Note: The measures in the first two rows follow the definitions of Aizenman and Jinjarak (2010); Aizenman et al. (2013). Tax base is calculated annually as general government revenue over GDP, averaged over the previous five years to account for business cycle fluctuations. The FB-ratio is calculated as: Government net fiscal balance over GDP, divided by tax base. The PD-ratio is calculated as: Government net debt over GDP, divided by tax base. The data have been obtained from the International Monetary Fund (2014).

ments and decisions positive if they involve efforts to raise the primary balance, and negative if they involve rejection of such efforts. At the European level, positive signals generally involve increased risk-sharing and provision of financial support to avoid defaults, while negative signals reflect actors' rejection of such measures. If such statements and decisions have any effect, positive signals should reduce spreads and negative signals should increase them, and given the considerable media attention afforded such signals during the period in question, one might indeed expect that they had effect. Nevertheless, our arguments suggest that investors may largely have ignored policy-making at the national level. In particular, the generally low perceived capacity of the GIIPS countries compared to European-level actors leads to the following expectation:

Hypothesis 1: The effects of key political signals at the national level are weaker than those of key signals at the European-level.

However, differences between the GIIPS countries and European-level actors add nuances to this expectation, and they also provide an additional opportunity to test our argument. While the capacities of the GIIPS were generally doubted during the crisis, some countries did better than others, and it is instructive to examine the countries' fiscal spaces, using the measures of Aizenman et al. (2013). Table 1 shows the average fiscal-balance-to-tax-base ratios and public-debt-to-tax-base ratios for the GIIPS over the period in question. In terms of debt, Greece was by far the worst placed country - just as it was before the crisis - while Ireland was the weakest in terms of fiscal balance. In contrast, Italy had by far the most favorable fiscal balance, while Spain had notably less debt than the other countries. As a simple, but convenient way to consider the two fiscal space measures together, Table 1 also shows their product, which further illustrates the already outlined picture: Italy and Spain had considerably more fiscal space than the other GIIPS countries, while Greece and Ireland were in particularly dire circumstances, leaving Portugal in the middle. 
We argue that investors and observers pay close attention to fundamentals and fiscal space measures, and that their assessments of countries' capacities are strongly influenced by these measures. ${ }^{6}$ This allows us to derive further predictions regarding the effects of national political signals. While it is interesting to analyze each country separately (and we report such analyses as supporting information), doing so is unattractive from a practical point of view, as it entails a significant loss of statistical power. To reduce this challenge, we group the countries according to their level of capacity, based on the measures discussed above. More specifically, we categorize Greece, Ireland, and Portugal as low capacity countries, and Italy and Spain as medium capacity countries (but it should also be noted that placing Portugal in the latter category would yield substantively similar results to those reported). Implementing our analysis separately for these groups of countries, our expectation is the following:

Hypothesis 2: The effects of national political signals are stronger in countries with higher capacity (medium rather than low).

This hypothesis is based on the assumption that the levels of capacity and willingness at the European-level are similar across the GIIPS countries, which deserves some further discussion. While we believe this assumption is plausible considering the EU and ECB together, the relative importance of the actors is likely to differ by country. First, it should be noted that while the capacity of the Eurozone countries to bail out the GIIPS is considerable, the extent to which they can let their own fiscal balances deteriorate is also limited. Thus, when it comes to large economies like Italy and Spain, questions have been raised as to whether these are too large to be bailed out. If this were a widely shared view, we might expect the effect of key EU signals (decisions) to be weaker in countries with larger economies. In contrast, as the ECB's capacity has fewer limitations, making it a particularly important actor for larger economies, we might expect the effect of key ECB signals (statements) to be stronger in countries with larger economies. While this is not the primary focus of this study, the analysis will also shed some light on how whether the effects of European-level signals vary in such a manner.

\section{Analysis}

Testing our hypotheses requires data on political events and other relevant news during the Eurozone debt crisis. We have thus collected a comprehensive new dataset covering the period from January 1, 2009, until December 31, 2012. Due to space constraints,

\footnotetext{
${ }^{6}$ This argument is consistent, for example, with the fact that a ranking of the countries in terms of CDS spreads during the crisis would give exactly the same pattern as that outlined above (for relevant CDS data, see Aizenman et al., 2013, 43).
} 
we will only briefly discuss these data here, while we provide a more detailed discussion as online supporting information. We employ two different sets of event data: One containing European-level events, and another containing country-specific national-level events. At both levels, we distinguish between political statements and decisions and code these as positive or negative. ${ }^{7}$ We further include a host of other events, which at the national level entail elections, protests, strikes, and other relevant news (e.g. regarding economic fundamentals or downgrades by rating agencies). At the European level, in addition to EU and ECB statements and decisions, we include statements and decisions by Germany, as well as ECB interest rate changes. This results in a total of 300 events at the European level, while we have 1036 at the national level.

As we are interested in the effects of particular events on financial time series, our analysis shares some features with most event studies. However, in contrast to most such studies, we analyze the effects of a large number of different event types, and we retain the time series format of our dependent variable. It would, for instance, not be feasible to implement the market model for normal returns, as there would rarely be a sufficient period of uninterrupted movement before the events to base the model on. In line with a number of existing studies (e.g. De Grauwe and Ji, 2013), we rather calculate daily spreads between the yields on 10-year bonds issued by the GIIPS-countries and the yields on similar German bonds. ${ }^{8}$ We further log-difference these series to capture continuously compounded returns, and we find that an $\operatorname{AR}(3)$ model with a $[0,1]$ event-window is appropriate. We analyze the data both as time series cross-sectional data (or panel data) and as separate time series. ${ }^{9}$ More detailed discussions of time series diagnostics, window selection, and model specification are provided as online supplementary information (due to space constraints).

To set up our model, we create binary event indicators for all observed combinations of signal direction, actor, and form. To simplify the presentation, let the vector $\mathbf{x}_{c t}$ contain the national level indicators for country $c$, and the vector $\mathbf{z}_{t}$ contain the European level indicators. To capture the $[0,1]$-window of interest, our model will include lagged versions of these vectors, as well as contemporaneous ones. In other words, we use a distributed lag (DL) model, estimating separate coefficients for each time point inside the window,

\footnotetext{
${ }^{7}$ At the European-level we also code mixed signals.

${ }^{8}$ Our data on bond yields contain daily closing values and originate from Thomson Reuters ECOWIN. Credit Default Swaps (CDS) would be an alternative measure, but recent studies conclude that bond spreads are more relevant (e.g. Badaoui et al., 2013). For further discussion of the relationship between default risk and bond spreads, see footnote 1 in the online supplementary information.

${ }^{9}$ While the inclusion of a lagged dependent variable gives rise to Hurwicz/Nickell-type bias, it should be noted that our estimator is still consistent in $T$. While such bias can pose a serious challenge for panels with very low $T$, the order of the bias is $1 / T$, and we have $T>1000$. Any bias will in other words be negligible and thus insufficient to justify the higher RMSE of alternative estimators.
} 
and thus avoid making assumptions regarding the specific impulse response within this time frame. ${ }^{10}$ As a safeguard to capture any remaining trends in the spreads, we also include a set of dummies capturing quarter-fixed effects, represented by the vector $\mathbf{q}_{t}$. We finally define the vector $\mathbf{v}_{c t}$ as $\left[y_{c t-1}, y_{c t-2}, y_{c t-3}\right]^{\prime}$, which allows the AR(3)DL panel model with a $[0,1]$-window to be expressed as:

$$
y_{c t}=\alpha+\mathbf{x}_{c t}^{\prime} \beta_{0}+\mathbf{x}_{c t-1}^{\prime} \beta_{1}+\mathbf{z}_{t}^{\prime} \pi_{0}+\mathbf{z}_{t-1}^{\prime} \pi_{1}+\mathbf{q}_{t}^{\prime} \gamma+\mathbf{v}_{c t}^{\prime} \rho+\varepsilon_{c t},
$$

where $y$ is the log-differenced bond spread, $\alpha$ is a constant, $\beta_{0}, \beta_{1}, \pi_{0}, \pi_{1}, \gamma$, and $\rho$ are vectors of coefficients, and $\varepsilon$ is an error term.

\section{Results}

To assess hypothesis 1, we start with a single model estimating average effects across the GIIPS-countries. Summary information regarding this model (1) is reported in table 2 , together with information about our other key models. The main results are shown in figure 1 , which reports cumulative effects over the $[0,1]$-window. ${ }^{11}$ (Please note that the figures only report theoretically relevant effects, while the full sets of estimates are reported in the appendix.) Starting with the negative national signals, these all have the expected sign, but neither political statements nor decisions have significant effects which must be seen in relation to the fact that negative signals (and negative decisions in particular) are rare. Negative news, in contrast, have a weak, but significant effect in the direction we would expect, increasing the spreads. Turning to positive national signals, the effect of positive decisions has the expected sign, but is barely below the threshold for significance at the $95 \%$ level of confidence. ${ }^{12}$ Neither the effect of positive news reaches statistical significance.

At the European level, we find strong and statistically significant effects for EU decisions and ECB statements, ${ }^{13}$ but not for EU statements and ECB decisions. This is consistent with the expectation that EU statements are largely ignored by the market,

\footnotetext{
${ }^{10}$ While multicollinearity can be a challenge for distributed lag models, generalized variance inflation factors show that this is a negligible issue in this case.

${ }^{11}$ For each type of event, the effect is calculated by adding the respective coefficients of the contemporaneous and lagged event indicators. To calculate the full cumulative effects, one would strictly speaking have to consider the impulse response functions implied by the auto-regressive components of our models, but we leave this issue aside here, as it is of minimal practical relevance and not substantively interesting. The full cumulative effects will be marginally larger than those reported here, which is also what we find if we implement a static model with a robust consistent covariance matrix.

${ }^{12}$ For similar results, showing no positive effect of national efforts to reassure markets, see Büchel (2013); McMenamin et al. (2015).

${ }^{13}$ These results stand in notable contrast to those of Smeets and Zimmermann (2013).
} 
Table 2: Summary Information for the Models Reported in Figures 1, 2, and 3.

\begin{tabular}{lcccccc}
\hline & Model 1 & Model 2 & Model 3 & Model 4 & Model 5 & Model 6 \\
\hline Reported in Figure & 1 & 2 & 2 & 3 & 3 & 3 \\
Countries & GIIPS & GIP & IS & GIIPS & GIIPS & GIIPS \\
AR $(l)$ & 3 & 3 & 3 & 3 & 3 & 3 \\
National events & Incl. & Incl. & Incl. & Incl. & Incl. & Incl. \\
European events & Incl. & Incl. & Incl. & Incl. & Incl. & Incl. \\
Placebo events & Excl. & Excl. & Excl. & Incl. & Incl. & Incl. \\
Quarter, Fixed Eff. & Incl. & Incl. & Incl. & Incl. & Incl. & Incl. \\
No. of Parameters & 65 & 65 & 65 & 91 & 67 & 91 \\
Observations & 5185 & 3111 & 2074 & 5185 & 5185 & 5185 \\
Event window & {$[0,1]$} & {$[0,1]$} & {$[0,1]$} & {$[-1,1]$} & {$[0,1]$} & {$[0,2]$} \\
HC cov. matrix & Yes & Yes & Yes & Yes & Yes & Yes \\
AR-test, $p$-value & 0.596 & 0.504 & 0.988 & 0.556 & 0.557 & 0.812 \\
\hline
\end{tabular}

Note: AR-test refers to a weighted Ljung-Box-type portmanteau test for serial correlation, using 8 lags (Fisher and Gallagher, 2012; Ljung and Box, 1978).

whereas ECB statements are more credible and thus seen as key signals. More importantly, hypothesis 1 receives strong support: The effects of key signals at the European level are considerably larger than those at the national level (where no political signals have significant effects). ${ }^{14}$ In substantive terms, the reported effects can be interpreted approximately as percentage changes (an effect of 0.05 implies a $4.88 \%$ change, while a 0.10 effect equals a $9.52 \%$ change). According to our estimates, if initial spreads (measured in percentage points) were at 6 , they would drop to 5.68 after a positive EU decision, and to 5.59 after a positive ECB statement.

To assess hypothesis 2, we estimate separate models for low and medium capacity countries (i.e. Greece, Ireland and Portugal versus Italy and Spain, respectively). These models are referred to as number 2 and 3 in table 2, and the main results are reported in figure 2. Starting with negative signals, the estimate for negative decisions is larger for the medium capacity countries, but neither estimate is significant. We further see that the effect of negative news is significant in the low capacity countries, although it is weak also here. Turning to positive national signals, where the number of observations is higher and the statistical power is greater, decisions again have a larger effect in countries

\footnotetext{
${ }^{14}$ The finding that national signals have no significant effects also discredits the potential counterhypothesis that national policy-making should matter for investors due to the conditionality inherent in EU bail-out programs. During the time period under consideration here, the market does not appear to have believed that the European actors would enforce very strict conditionality. In the case of Greece, this may of course have changed after the party Syriza with its anti-austerity position entered government in January 2015. Negotiating with this new government, the European actors appeared much stricter in June and July 2015 than in earlier years. Here, however, we focus on the period ending in 2012, when this was less relevant.
} 
Figure 1: General Results across the GIIPS Countries.

Negative National Signals

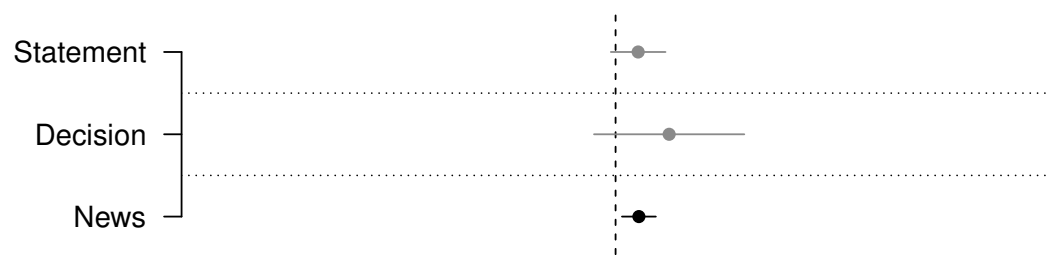

Positive National Signals

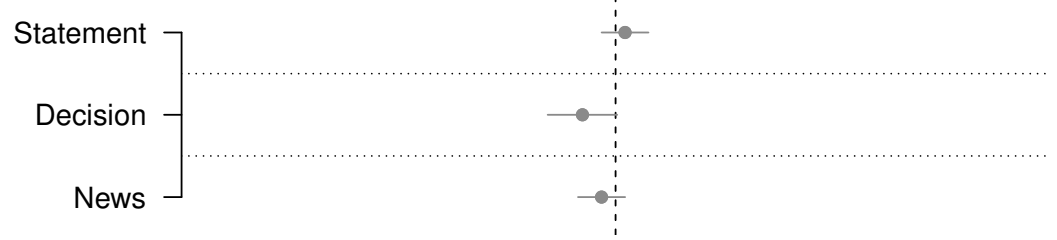

Positive European Signals

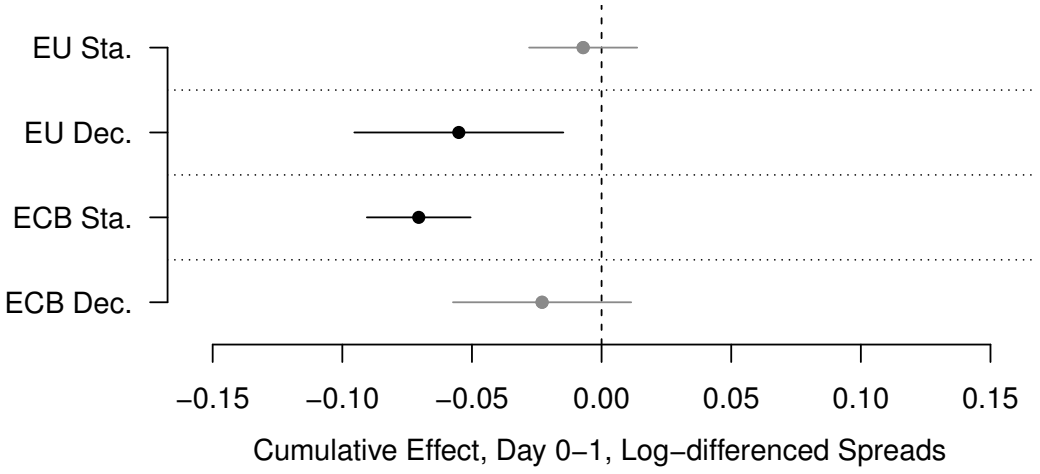

Note: This figure only reports theoretically relevant effects, while the complete results are provided as supplementary information. The error bars give $95 \%$ confidence intervals; statistically significant estimates are shown in black, insignificant ones in gray. The standard errors are calculated using generally heteroskedasticity consistent covariance matrices.

with medium rather than low capacity. This is consistent with hypothesis 2 , but while the estimate for the countries with higher capacity is significantly different from zero, it is not significantly different from the estimate for the low capacity countries, precluding any strong conclusions in this regard. Lastly, we see that positive news also have a significant effect in these countries.

As mentioned, we may also expect differences in the impact of European-level signals. First, EU signals could matter less in larger economies (i.e. the same countries that we categorize as having medium capacity, namely Italy and Spain). However, this notion receives no support, as the estimated effects of EU decisions are virtually identical in our two groups of countries, and the estimate in the low capacity countries barely fails to reach statistical significance. It seems investors consider EU decisions as relevant signals regarding default risk even in the largest economies, despite some observers' worries that these are too large to be bailed out. Lastly, we might expect ECB signals to matter more in larger countries, as the ECB's capacity has fewer limits, making the ECB a 
Figure 2: Results by National Capacity to Avoid Default.

Negative National Signals

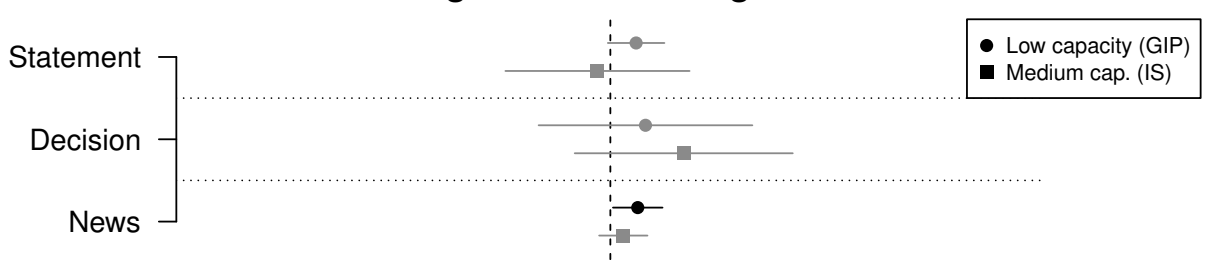

Positive National Signals

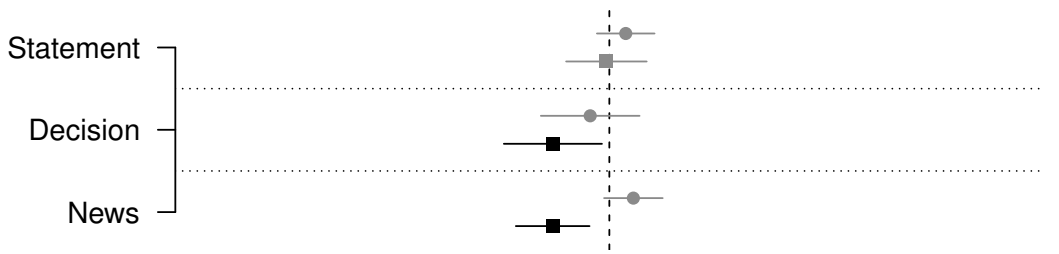

Positive European Signals

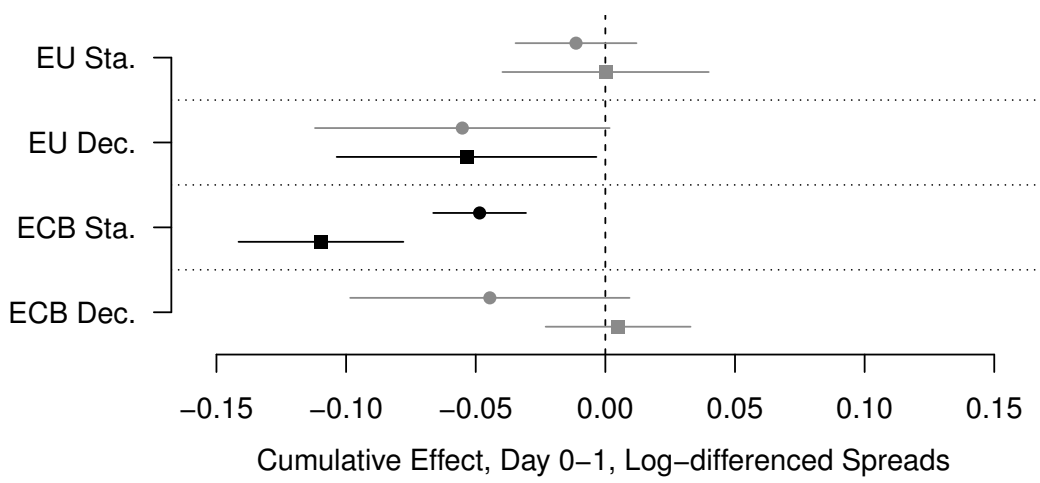

Note: This figure only reports theoretically relevant effects, while the complete results are provided as supplementary information. Low capacity refers to Greece, Ireland and Portugal; Medium capacity refers to Italy and Spain. The error bars give $95 \%$ confidence intervals; statistically significant estimates are shown in black, insignificant ones in gray. The standard errors are calculated using generally heteroskedasticity consistent covariance matrices.

particularly important actor for these countries. This notion does indeed receive support, as the estimate for the larger countries is considerably larger than that for the smaller ones.

Having presented the results of our main models, we will briefly discuss the robustness of our results. While there are strong theoretical (and empirical) reasons to expect the events in our data mainly to have effects within the $[0,1]$-window, it is worth checking whether alternative windows would yield notably different results. We thus report (as supplementary information) analyses expanding the event window one day in each direction, and we find that the results are very robust to these alternative specifications. Furthermore, while the focus of this paper is not on the issue of potential contagion, it is worth noting that the results still hold if we control for national-level events taking place in the other GIIPS countries. This is in line with the finding that such such events have limited effects even for the countries in which they take place. It is also worth assess- 
ing whether our approach to address auto-regressive heteroskedasticity (ARCH) is valid, and examine how the results would look if the analysis were implemented by country. We thus report (as supplementary information) country-specific OLS and $\operatorname{GARCH}(1,1)$ models, showing that the results are comparable across countries and that GARCH and OLS models yield similar results.

Lastly, we conduct a placebo test to increase our confidence in the results. ${ }^{15}$ For many of the event types we examine, not least statements, it would be difficult to identify relevant placebo treatments. Yet, for one event type of notable theoretical importance, namely EU decisions, this task is more straightforward. More specifically, we examine EU meetings that did not lead to decisions or statements of relevance to international bond markets. We have 10 such 'no decision'-meetings occurring from March 2, 2009 until November 23, 2012. The rationale of our test is as follows: As explained above, we argue that markets react to the content of EU decisions - spreads drop when positive decisions are made. One could, however, speculate that EU meetings coincide with other factors that truly move the markets, or that markets simply react to the fact that a meeting is held. Alternatively, the results could be some kind of methodological artifact. For each of the three event windows used in the robustness checks, we thus re-estimate our model, including EU meetings without relevant decisions. Summary information for these three models is reported in table 2 , and the results are shown in figure 3 . As the figure shows, the placebo meetings are not found to have significant effects in any of the models, in contrast to the meetings with positive decisions. This increases our confidence that these results represent valid causal inferences.

\section{Conclusion}

The Eurozone debt crisis underlined how important it is - and how difficult it can be - for states to maintain the trust of bond markets, but existing studies still provide few answers as to when policy-makers can succeed at this task. This study contributes towards answering this question by presenting theoretical arguments regarding the effects of political signals both from national and international actors. Our main argument is that investors distinguish between actors' capacity and willingness to avoid defaults when determining the relevance of their signals. A key point is that avoiding default requires both sufficient capacity and willingness to do so, and that the lower an actor's perceived capacity is, the less important this actor's perceived willingness becomes. In addition,

\footnotetext{
${ }^{15}$ Different authors present different types of placebo tests, some focusing on placebo treatments, others outcomes. The tests do, however, generally share the feature that finding placebo effects would undermine the credibility of the research design, which is also the case here, where we focus on placebo treatments.
} 
Figure 3: Placebo Tests for EU Meetings

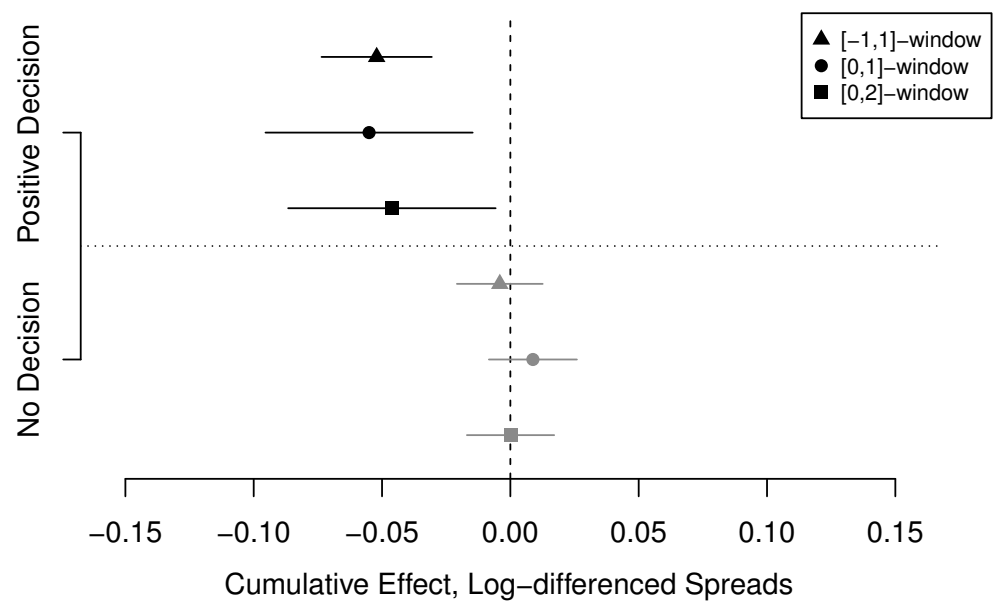

Note: This figure only reports effects relevant to the placebo test, while the complete results are provided as supplementary information. The error bars give 95\% confidence intervals; statistically significant estimates are shown in black, insignificant ones in gray. The standard errors are calculated using generally heteroskedasticity consistent covariance matrices.

the perceived probability of there being both sufficient capacity and willingness at the international level (which we refer to as secondary trust), becomes more important as the equivalent probability at the national level (primary trust) decreases.

Applying this argument to the Eurozone, we argue that the debt crisis was triggered by a perceived lack of capacity on part of the GIIPS-countries, which limited the relevance of their willingness. The low capacity of these countries was partly due to their limited fiscal space (high debts and deficits relative to their tax base), but they were also particularly weak due to their EMU membership, which removed their ability to conduct their own monetary policy. Conversely, the European-level actors had greater capacities than international actors have in most other cases. Thus, the issue undermining investors' secondary trust was not the question of whether European-level actors had the capacity to prevent defaults, but whether they were actually willing to do so, amidst resurfacing nationalist sentiments and questions of whether bail-outs were permitted by existing European treaties and national legal frameworks.

Accordingly, we find considerably larger effects of political signals at the European level than the national level. ${ }^{16}$ Our findings are largely consistent with the very few existing studies looking at related questions, and our theoretical arguments thus help explain the findings of these earlier studies, but we also add further nuances by predicting differences among the actors at each level. We note, for example, that a couple of countries

\footnotetext{
${ }^{16}$ While this finding is in line with our expectations, it should be treated with some caution. Our datasets were collected in two different ways, which could potentially undermine comparability across levels (even if each separate dataset has high validity and reliability).
} 
(Italy and Spain) had somewhat more capacity than the others, which should make their political decisions more important to investors. We also argue that the ECB is particularly important for larger economies, due to its extensive capacity, and we do indeed find larger effects of ECB statements in the two largest GIIPS economies.

Turning to the implications of our arguments, it is worth noting that, while we argue that the distinction between capacity and willingness is relevant and useful - because it is applied by investors and observers - it is not necessarily clear-cut. While capacity can be considered given at any specific point in time - defining the options available - the distinction between factors that can be influenced by the actors and those that cannot is hard to sustain over a longer time frame. In the long-run, it may be more accurate to say that an actor's capacity depends on its previous course of action. This is particularly important at the national level: The notion that a state needs sufficient capacity to avoid defaulting also implies that it needs to maintain this capacity by adjusting its finances in good time - once its capacity is questioned, it may be too late. These points do not change the argument that rating agencies and investors distinguish between capacity and willingness, but future research should examine exactly where they draw the line between the two.

As mentioned, the Eurozone is particular in how the existence of a common central bank weakens the capacity of national actors and strengthens the influence of external actors. In this setting, with considerable capacity residing at the European-level, it is vital that the actors at this level are willing to share the responsibility for guaranteeing sovereign debt. While this situation sets Eurozone members apart from most other countries, our general arguments can easily be applied also to other cases: Even where external actors (such as the IMF) are weaker, default risk is partly a function of the probability that they will prevent defaults when national actors fail to do so. Furthermore, when assessing the probability that national and international actors will succeed at preventing defaults, we would generally expect investors to separately assess the actors' capacity and willingness.

Lastly, it could be noted that this topic is intrinsically linked to economic crises: It is when investors lose faith in sovereign debtors that we will see explicit efforts to reassure them, and it is also at this time that such efforts are likely to have the greatest effect (if they are successful). Our study has focused on a time of exceptional volatility in Europe's sovereign debt market, and during another time period we would neither observe as many relevant events, nor expect them to have as strong effects as we find for some events in this study. In fact, political signals may already matter less for European bond markets than they did during the period examined here, but we leave this for future research to assess. 


\section{References}

Aizenman, J., Hutchison, M. and Jinjarak, Y. (2013) 'What is the risk of European sovereign debt defaults? Fiscal space, CDS spreads and market pricing of risk'. Journal of International Money and Finance, Vol. 34, No. 0, pp. 37-59.

Aizenman, J. and Jinjarak, Y. (2010) 'De facto Fiscal Space and Fiscal Stimulus: Definition and Assessment', Working Paper No. 16539., National Bureau of Economic Research.

Badaoui, S., Cathcart, L. and El-Jahel, L. (2013) 'Do sovereign credit default swaps represent a clean measure of sovereign default risk? A factor model approach'. Journal of Banking and Finance, Vol. 37, No. 7, pp. 2392-2407.

Bechtel, M. M., Hainmueller, J. and Margalit, Y. (2014) 'Preferences for International Redistribution: The Divide over the Eurozone bailouts'. American Journal of Political Science, Vol. 58, No. 4, pp. 835-856.

Bechtel, M. M. and Schneider, G. (2010) 'Eliciting Substance from 'Hot Air': Financial Market Responses to EU Summit Decisions on European Defense.' International Organization, Vol. 64, No. 2.

Beetsma, R., Giuliodori, M., de Jong, F. and Widijanto, D. (2013) 'Spread the news: The impact of news on the European sovereign bond markets during the crisis'. Journal of International Money and Finance, Vol. 34, No. 0, pp. 83-101.

Beirne, J. and Fratzscher, M. (2013) 'The pricing of sovereign risk and contagion during the European sovereign debt crisis'. Journal of International Money and Finance, Vol. 34, No. 0, pp. 60-82.

Bera, A. K., Sosa-Escudero, W. and Yoon, M. (2001) 'Tests for the Error Component Model in the Presence of Local Misspecification'. Journal of Econometrics, Vol. 101, No. 1, pp. 1-23.

Bernoth, K. and Erdogan, B. (2012) 'Sovereign bond yield spreads: A time-varying coefficient approach'. Journal of International Money and Finance, Vol. 31, No. 3, pp. 639-656.

Bølstad, J. and Elhardt, C. (2015) 'To Bail Out or Not to Bail Out? Crisis Politics, Credibility, and Default Risk in the Eurozone'. European Union Politics, Vol. 16, No. 3.

Borensztein, E. and Panizza, U. (2009) 'The Costs of Sovereign Default'. IMF Staff Papers, Vol. 56, No. 4, pp. 683-741. 
Breen, M. and McMenamin, I. (2013) 'Political Institutions, Credible Commitment, and Sovereign Debt in Advanced Economies'. International Studies Quarterly, Vol. 57, No. 4, pp. $842-854$.

Büchel, K. (2013) 'Do words matter? The impact of communication on the PIIGS' CDS and bond yield spreads during Europe's sovereign debt crisis'. European Journal of Political Economy, Vol. 32, No. 0, pp. 412-431.

Cantor, R. and Packer, F. (1996) 'Determinants and Impact of Sovereign Credit Ratings'. Economic Policy Review, Vol. 2, No. 2, pp. 37-54.

De Grauwe, P. (2013) 'The European Central Bank as Lender of Last Resort in the Government Bond Markets'. CESifo Economic Studies, Vol. 59, No. 3, pp. 520-535.

De Grauwe, P. and Ji, Y. (2012) 'Mispricing of Sovereign Risk and Macroeconomic Stability in the Eurozone'. JCMS: Journal of Common Market Studies, Vol. 50, No. 6, pp. 866-880.

De Grauwe, P. and Ji, Y. (2013) 'Self-fulfilling crises in the Eurozone: An empirical test'. Journal of International Money and Finance, Vol. 34, No. 0, pp. 15-36.

De Haan, L., Hessel, J. and van den End, J. W. (2014) 'Are European sovereign bonds fairly priced? The role of modelling uncertainty'. Journal of International Money and Finance, Vol. 47, No. 0, pp. 239-267.

Eaton, J. and Gersovitz, M. (1981) 'Debt with Potential Repudiation: Theoretical and Empirical Analysis'. The Review of Economic Studies, Vol. 48, No. 2, pp. pp. 289-309.

Eaton, J., Gersovitz, M. and Stiglitz, J. E. (1986) 'The Pure Theory of Country Risk'. European Economic Review, Vol. 30, No. 3, pp. 481-513.

Fisher, T. J. and Gallagher, C. M. (2012) 'New Weighted Portmanteau Statistics for Time series Goodness of Fit Testing'. Journal of the American Statistical Association, Vol. 107, No. 498, pp. 777-787.

Ghosh, A. R., Ostry, J. D. and Qureshi, M. S. (2013) 'Fiscal space and sovereign risk pricing in a currency union'. Journal of International Money and Finance, Vol. 34, No. 0, pp. 131-163.

Goldbach, R. and Fahrholz, C. (2011) 'The Euro area's common default risk: Evidence on the Commission's impact on European fiscal affairs'. European Union Politics, Vol. 12, No. 4, pp. 507-528.

Hatchondo, J. C., Martinez, L. and Sapriza, H. (2007) 'The economics of sovereign defaults'. Economic Quarterly, Vol. 93, No. 2, p. 163. 
Heller, P. (2005) 'Back to Basics - Fiscal Space: What it is and how to get it'. Finance and Development, Vol. 42, No. 2, pp. 32-33.

International Monetary Fund (2014) 'World Economic Outlook Database, October 2014'. Available at <http://www.imf.org/external/pubs/ft/weo/2014/02/weodata/ index.aspx $>$. Accessed 20 December 2014.

Ljung, G. M. and Box, G. E. (1978) 'On a measure of lack of fit in time series models'. Biometrika, Vol. 65, No. 2, pp. 297-303.

McMenamin, I., Breen, M. and Muñoz-Portillo, J. (2015) 'Austerity and credibility in the Eurozone'. European Union Politics, Vol. 16, No. 1, pp. 45-66.

Mendoza, E. G. and Yue, V. Z. (2012) 'A General Equilibrium Model of Sovereign Default and Business Cycles'. The Quarterly Journal of Economics, Vol. 127, No. 2, pp. 889946.

Mink, M. and de Haan, J. (2013) 'Contagion during the Greek sovereign debt crisis'. Journal of International Money and Finance, Vol. 34, No. 0, pp. 102-113.

Mosley, L. (2004) 'Government-Financial Market Relations after EMU: New Currency, New Constraints?' European Union Politics, Vol. 5, No. 2, pp. 181-209.

Panizza, U., Sturzenegger, F. and Zettelmeyer, J. (2009) 'The economics and law of sovereign debt and default'. Journal of Economic Literature, pp. 651-698.

Paterson, W. E. (2011) 'The Reluctant Hegemon? Germany Moves Centre Stage in the European Union'. JCMS: Journal of Common Market Studies, Vol. 49, No. s1, pp. $57-75$.

Smeets, D. and Zimmermann, M. (2013) 'Did the EU Summits Succeed in Convincing the Markets during the Recent Crisis?' JCMS: Journal of Common Market Studies, Vol. 51, No. 6, pp. 1158-1177.

Stasavage, D. (2011) States of Credit: Size, Power, and the Development of European Polities (Princeton University Press).

Tomz, M. (2007) Reputation and international cooperation: Sovereign debt across three centuries (Princeton University Press). 


\section{Supplementary Information}

\section{Contents}

1 A More Detailed Argument 1

2 Data on National Events 3

3 Data on European Events 5

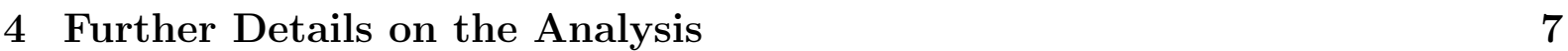

5 Robustness Checks $\quad 8$

6 Complete Results for All Models $\quad 12$

This material belongs to the following article:

Bølstad, J. and Elhardt, C. (2017) 'Capacity, Willingness, and Sovereign Default Risk: Reassuring the Market in Times of Crisis'. JCMS: Journal of Common Market Studies. 


\section{A More Detailed Argument}

We argue that an adequate model of default risks needs to account for the willingness and capacity to avoid default of actors both at the national and the international level. A country's probability of default is therefore best understood as a function of several more specific probabilities. First, in line with the existing literature, we argue investors have to assess the probability that countries are willing and able to service their debt in full (without external support). We refer to the subjective assessment of this probability as primary trust and denote it by $\phi \in(0,1)$. However, investors also have to assess the probability that a country will be rescued by external actors in case it is no longer able to service its liabilities on its own, which we refer to as secondary trust and denote by $\eta \in(0,1)$. In sum, investors' overall probability of being paid in full $(\tau)$ is the combined probability of a country remaining solvent and the country being rescued in the event of insolvency:

$$
\tau=\phi+\eta(1-\phi)
$$

Drawing upon the research outlined in the main text, we further argue that investors distinguish between actors' capacity and willingness to avoid defaults. Such considerations are, for instance, evident in the methodologies of the major rating agencies, who assess not only countries' debt servicing capacities, but also political risk - even if the latter is largely assessed qualitatively or by way of proxies (see, for instance, Standard and Poor's, 2011; Moody's, 2013). We define actors' capacity as their scope for avoiding default, and we consider this scope at any particular time point as given, representing factors that lie outside of the actors' control. At the national level, capacity is necessarily linked to the notion of fiscal space, while at the international level, other considerations are more relevant, as we discuss in the main text. We further define actors' willingness to avoid default as their intended use of their capacity - whether they will indeed avoid defaults if they have the capacity to do so. For national governments, this involves implementing necessary reforms and raising the primary balance of the budget as the cost of debt servicing grows. In contrast, at the international level, this concept entails the willingness to bear the costs of providing sufficient support to prevent the default of illiquid or insolvent countries.

While we let capacity represent factors outside of governments' control, we argue that willingness (or the lack of it) can be signaled through relevant statements and decisions, and the focus of this study is the question of when such signals are effective at shaping investors' trust. We argue not only that investors assess both capacity and willingness, but also that sufficient capacity and willingness are considered to be individually necessary and jointly sufficient conditions for successful efforts to avoid default. Thus, if we let 
$\kappa \in(0,1)$ denote the probability that there is sufficient national capacity, and similarly use $\theta \in(0,1)$ for national willingness (conditional on sufficient capacity), $\lambda \in(0,1)$ for international capacity, and $\mu \in(0,1)$ for international willingness (conditional on sufficient capacity), then $\phi=\kappa \theta$, and $\eta=\lambda \mu$. Substituting these definitions for $\phi$ and $\eta$ in equation 1, we get: 1

$$
\tau=\kappa \theta+\lambda \mu(1-\kappa \theta)
$$

A key implication of this model is that the effect of signals regarding an actor's willingness is conditioned by this actor's capacity. The precise nature of this interaction becomes clearer if we take partial derivatives of equation 2. With respect to national willingness, this yields:

$$
\frac{\delta \tau}{\delta \theta}=\kappa-\lambda \mu \kappa,
$$

while we get the following with respect to international willingness:

$$
\frac{\delta \tau}{\delta \mu}=\lambda-\lambda \kappa \theta
$$

The most straightforward implication is that the impact of changes in the perceived willingness of an actor is a positive function of this actor's capacity: $\frac{\delta \tau}{\delta \theta}$ is a positive function of $\kappa$, and $\frac{\delta \tau}{\delta \mu}$ is a positive function of $\lambda$, as $\kappa>\lambda \mu \kappa$ and $\lambda>\lambda \kappa \theta$. Put differently, as an actor's capacity declines, the relevance of this actor's willingness (and signals regarding this

\footnotetext{
${ }^{1}$ The relationship between default risk $(1-\tau)$ and bond yields is fairly straightforward. For a zerocoupon bond with only one cash flow $(C)$ at maturity $(M)$, the expected cash flow is $E[C]=\tau C$. (For convenience, we let the recovery rate be zero in this discussion.) The yield to maturity is $Y=\sqrt[M]{C / P}-1$, where $P$ is the price, while the expected rate of return is $E[R]=\sqrt[M]{E[C] / P}-1$. To keep the expected rate of return constant as the risk of default increases, the price must drop and the yield increase accordingly: $P_{1} / P_{0}=E[C]_{1} / E[C]_{0}$. For a risk-neutral investor, this would be sufficient to maintain a bond's attractiveness.

While we focus on default risk as a key determinant of bond spreads (which is consistent with the extremely strong relationship between CDS spreads and bond spreads, both over time and across issuers), other potential factors such as liquidity, taxability, and general risk aversion also deserve some consideration. First, it is worth noting that we analyze daily changes, and thus difference out any permanent differences in taxability or liquidity. Such factors are only relevant in so far as they show daily changes, and they only threaten our inferences in so far as they also covary with our events, yet do so for exogenous reasons - which is unlikely. Put differently, if there are daily shifts in either general risk aversion or concerns over liquidity that systemically covary with our events, then they are also likely to be caused by them. This is consistent with the fact that our placebo test for EU meetings (which is one of the events for which we find the strongest effects) gives no indication that the results are confounded. It is further worth noting we are mainly interested in the overall effects of political actions. While we cannot rule out that a minor part of the effects are due to an alternative mechanism, such as changed perceptions or expectations regarding liquidity, rather than perceptions of default risk, this would not change our conclusions regarding the effects of the events in question.
} 
willingness) is also diminished (all else equal). Yet the importance of willingness at one level also decreases as capacity or willingness at the other level increases, and vice versa. In fact, $\lim _{\lambda \mu \rightarrow 1} \frac{\delta \tau}{\delta \theta}=0$, and $\lim _{\kappa \theta \rightarrow 1} \frac{\delta \tau}{\delta \mu}=0$, while $\lim _{\lambda \mu \rightarrow 0} \frac{\delta \tau}{\delta \theta}=\kappa$, and $\lim _{\kappa \theta \rightarrow 0} \frac{\delta \tau}{\delta \mu}=\lambda$. If, for instance, national capacity decreases, this will not only reduce the effect of changes in national willingness, but also increase the impact of changes in international willingness. Comparing the two levels, we see that $\frac{\delta \tau}{\delta \mu}>\frac{\delta \tau}{\delta \theta}$ when $\lambda-\kappa>\lambda \kappa(\theta-\mu)$ and $\frac{\delta \tau}{\delta \mu}<\frac{\delta \tau}{\delta \theta}$ when $\lambda-\kappa<\lambda \kappa(\theta-\mu)$. This is worth keeping in mind, as it qualifies the intuitive expectation that effects will be greater for actors with greater capacity.

\section{Data on National Events}

In the following, we describe our data in more detail. Starting with the national level, we distinguish between positive and negative signals, coding whether they took the form of statements or decisions. Positive national signals indicate a country's willingness to avoid default by raising the primary balance of its budget and maintaining sustainable public finances. More specifically, this includes statements and decisions to reduce the public deficit in the medium term through various pay and benefit cuts, tax rises, the privatization of state assets, the reduction of tax evasion as well as more structural reforms that aim to increase a country's growth prospects and thus improve its debt-to-GDP-ratio in the longer term. Negative signals, in contrast, indicate a country's limited willingness to ensure the sustainability of its public finances. Here, we include statements and decisions that imply the failure to agree on - or implement - various austerity measures and growthenhancing reforms, as well as political resistance within the government or parliament against spending cuts, tax rises or structural reforms, and, lastly, the acceptance of any form of debt restructuring - be it voluntary or not.

Our main data source is the online archive of the Financial Times (FT). ${ }^{2}$ The FT's webpage does not only contain the articles of the daily print edition but also additional articles by FT writers and material published on the FT' blogs. As one of the world's leading newspapers on economics and business, with an extensive coverage of European politics and markets, we argue that the FT covers the most important political and economic events in the GIIPS - indeed, the FT is itself a major source of information for investors interested in European bond markets. ${ }^{3}$ To identify relevant articles, we performed a content analysis using the FT's own online search tool, proceeding in two steps.

\footnotetext{
${ }^{2}$ Available at $<$ www.ft.com $>$.

${ }^{3}$ As some might worry that FT as British newspaper would give disproportionate attention to events in Ireland, it is worth noting that the coding does not yield more events for Ireland than for the other countries.
} 
First, we performed a search for news articles on each of the GIIPS countries, published between January 1, 2009 and December 31, 2012, using a combination of keywords such as "Greek" and "Greece" for each respective country. This yielded a very large amount of news articles, which we then - in a second step - coded manually according to our theoretically relevant categories. ${ }^{4}$

As the main aim was to code signals regarding the national willingness to avoid default, our coding focused on statements and decisions by the government, the parliament or key policy makers representing these institutions. Most of the coded news articles were thus either referring to the decisions of collective actors such the national government or parliament, or statements by top officials such as a given country's Prime Minister or Finance Minister. Two brief examples may serve to illustrate our coding strategy: On October 2, 2011, the FT reported "Greek cabinet approves budget cuts" 5 while on June 6, 2011, it reported that Portugal's prime minister was prepared to "go beyond" the country's bail-out agreement. ${ }^{6}$ While the first instance was coded as a positive decision, the second was coded as a positive statement.

Our aim is not only to include the key signals of theoretical interest, but also to include all other key events that are likely to influence the outcomes in question. We have therefore also coded relevant positive and negative national news, as well as elections, protests, and strikes. The negative national news category includes such news as downgrades by the three major rating agencies (Standard \& Poors, Fitch, and Moody's), the publication of new economic data or forecasts pointing to weaker debt metrics and growth prospects, falling banking stocks and funding problems of banks, failed stress test by banks, weaker performance of national companies, problems with the privatization of state assets, an increase of public deficits by regions, and the evidence of increasing capital flight. The positive news category contains the logical opposites of such elements.

Overall, our national dataset contains 1036 events, of which 107 are negative political signals, and 310 are positive signals, while the remaining 619 are additional events that we include as controls in the analysis. Table S1 shows how these events are distributed across our theoretical categories for each of the GIIPS countries. It is noticeable that

\footnotetext{
${ }^{4}$ As certain events can give rise to several news stories, we code a given event as taking place on the first day on which it is reported in the news (while similar reports on the following days have been excluded). For most events, such coding is fairly straightforward. In our analyses, we also address this issue by allowing events to have effects on the following day, as well as the day on which they are first reported. This window is further expanded in the robustness checks.

${ }^{5}$ Available at <http://www.ft.com/intl/cms/s/0/17955778-ed13-11e0-be97-00144feab49a.html\# axzz2vGyQ3NqG $>$.

${ }^{6}$ Available at <http://www.ft.com/intl/cms/s/0/81acf4b0-9064-11e0-9227-00144feab49a.html\# axzz38w1YrgG1>.
} 
policy makers generally avoid making negative decisions that might call into question their willingness to avoid a default and thus increase the yields they have to pay. Furthermore, the fact that there are almost three times more positive political signals than negative ones suggests that policy makers are genuinely concerned about preserving investors' trust. From a more practical perspective, the relative lack of negative signals (and negative decisions, in particular) makes it harder to test the effect of these signals, and our analysis and discussion will thus be more focused on positive signals - and efforts to reassure the markets.

Table S1: Number of Events at the National Level by Event Type.

\begin{tabular}{l|ccccc|c}
\hline & Greece & Italy & Ireland & Portugal & Spain & Total \\
\hline Sta.Gov.Neg & 44 & 7 & 19 & 17 & 6 & 93 \\
Dec.Gov.Neg & 7 & 4 & 0 & 1 & 2 & 14 \\
NA.News.Neg & 28 & 61 & 92 & 60 & 115 & 356 \\
Sta.Gov.Pos & 85 & 25 & 11 & 22 & 46 & 189 \\
Dec.Gov.Pos & 29 & 22 & 17 & 22 & 31 & 121 \\
NA.News.Pos & 18 & 30 & 41 & 30 & 50 & 169 \\
NA.Prot.Mix & 41 & 13 & 4 & 8 & 12 & 78 \\
NA.Elec.Mix & 4 & 3 & 1 & 2 & 6 & 16 \\
\hline Total & 256 & 165 & 185 & 162 & 268 & 1036 \\
\hline Note: "Sta." refers to statements, "Dec." to decisions, and "NA" to events \\
that fit neither category; "Gov." refers to signals by the national government \\
or parliament, "News" to nationally relevant news, "Prot." to protests, and \\
"Elec." to national elections; "Neg." refers to negative signals, "Neg." to \\
negative, and "Mix." to mixed ones. Protests and elections are included as \\
controls in the analysis, but not discussed as events of theoretical interest.
\end{tabular}

\section{Data on European Events}

Turning to the European-level, we rely on data from Bølstad and Elhardt (2015). ${ }^{7}$ These data contain relevant statements and decisions by the EU (the European council, the ECOFIN and the Euro-group), as well as statements and decisions by the ECB. ${ }^{8}$ Consistent with our coding at the national level, we distinguish between positive and negative European statements and decisions, but we also add a category to encompass mixed sig-

\footnotetext{
${ }^{7}$ We make a few adjustments to these data, however: We leave aside decisions and statements by rating agencies, as these are also covered by our national-level data, and we add EU meetings that failed to produce relevant decisions, which serve as placebo tests.

${ }^{8}$ Some of the EU decisions in the data also involved the IMF, but the IMF's contributions represented a minor share of all programs, and the IMF played a role in only 7 out of all 55 events we coded for the EU. Likewise, Ireland's rescue package also included minor contributions by the UK, Denmark and Sweden. However, as these contributions were all announced on the same days, their effects are indistinguishable, and as the EU's contributions were by far the largest, we still refer to these events as EU decisions.
} 
nals. ${ }^{9}$ Positive signals generally reflect the EU's and the ECB's willingness to provide financial support to the GIIPS and to engage in forms of risk-sharing in order to avoid any restructuring of - or outright default on - sovereign debt by any member of the Eurozone. This includes statements and decisions to bail-out troubled Eurozone economies, to set-up or increase the EFSF (European Financial Stability Facility) or the ESM (European Stability Mechanism), to mutualize debt in the form of Eurobonds or to set up a common deposit insurance scheme for Eurozone banks. For the ECB, we also include statements and decisions relating to its Security Markets Program (SMP), and the Outright Monetary Transactions (OMT), as these programs aim to reassure markets that temporarily illiquid governments will not be forced to default on their debt. In contrast, negative signals reflect actors' reluctance towards all these measures and their acceptance of debt restructuring or defaults inside EMU.

To ensure a comprehensive and complete coverage, the dataset is based on a triangulation of several sources: It combines information obtained from a daily newsflash covering key events in the Eurozone (Eurointelligence, 2014) with the European Commission's own online chronology of the Euro-crisis (European Commission, 2014), as well as two lists of crisis related events provided by Smeets and Zimmermann (2013) and the think-tank Bruegel (2014). As shown in table S2, our European-level dataset contains 28 statements and decisions by the ECB and 45 by the EU. It is also worth noting that it is extremely rare for these actors to send purely negative signals, whether they are statements or decisions. ${ }^{10}$ This again illustrates how actors' efforts have centered on reassuring (rather than upsetting) the market. Put differently, the distribution of signals illustrates that the main question at the European level was whether the actors were willing to move forward in sharing the responsibility for guaranteeing Eurozone debt, or whether they would maintain the status quo and risk national defaults.

\footnotetext{
${ }^{9}$ We code signals as mixed if they include both positive and negative elements. An example is the following statement by the Eurozone released on the Commission's online chronology of the crisis: "European leaders announce that they are willing to prepare a financial assistance package to Greece, in cooperation with the IMF. However, they also announce that this assistance should be considered 'ultima ratio', and would be provided at explicitly punitive interest rates to encourage a quick return to market financing". This information is available at <http://www.consilium.europa.eu/uedocs/cms_data/docs/ pressdata/en/ec/113563.pdf $>$.

${ }^{10}$ It should be noted that we exclude three events from the analysis, as they each represent the only occurrence of their type of event. Two of these events also took place on the same day: On February 29, 2012, the ECB and Germany each made their only negative decisions, making it impossible to distinguish their effects. The other event we leave aside in the analysis is a mixed German decision, which neither makes for reliable estimation as it was only observed once. Including these events in the analysis would not change the reported results, however.
} 
Table S2: Number of Events at the European Level by Event Type.

\begin{tabular}{l|ccc|ccc|cc|c}
\hline & \multicolumn{3}{|c|}{ Negative } & \multicolumn{3}{c|}{ Positive } & \multicolumn{2}{c|}{ Mixed } & Total \\
\hline & Sta. & Dec. & Int. & Sta. & Dec. & Int. & Sta. & Dec. & \\
\hline Germany & 133 & 0 & 0 & 19 & 11 & 0 & 64 & 0 & 227 \\
EU & 2 & 0 & 0 & 4 & 13 & 0 & 13 & 13 & 45 \\
ECB & 2 & 0 & 2 & 3 & 13 & 6 & 2 & 0 & 28 \\
\hline Total & 137 & 0 & 2 & 26 & 37 & 6 & 79 & 13 & 300 \\
\hline Note: "Sta." refers to statements, "Dec." to decisions, and "Int." to ECB interest \\
rate decisions. Decisions of the latter type, as well as German statements and \\
decisions, are included as controls in the analysis, but not discussed as events of \\
theoretical interest.
\end{tabular}

\section{Further Details on the Analysis}

This section provides information for which there was insufficient space in the main text. First, we make a few adjustments that are worth noting. In line with most other studies of financial time series, we ignore non-trading days, and treat the data as a continuous time series of trading days. Consistent with this approach, we move all events that take place on non-trading days to the first subsequent trading day, which is the first day on which such events can take effect. At the European level, this applies to 12 events, 8 of which are moved one day, while the remaining 4 are moved two days. At the national level, 93 events are moved one day, 23 are moved two days, and one is moved three days.

A key issue in this study, as in most event studies, is the selection of an event window, within which the effects of an event is analyzed. Theoretically, we would expect financial markets to react very rapidly to relevant news, pricing in new information on the same day as it is released $(t=0)$. However, if news are released late in the day, or investors' decisions are delayed, one might also expect to see some effect on the subsequent day $(t=1)$. This issue can also be assessed empirically: If we select "isolated events" that do not take place close to any other important events, we find that the spreads in question indeed do react according to the expected pattern - mostly on the same day as the events, but also on the next day. We thus focus on a [0-1]-window in our analyses, but (in this appendix) we also report robustness checks, expanding this window in each direction.

Our outcome variable, $y$, also requires some more consideration. While the initial spreads series are integrated, the differencing provides series with only moderate serial dependency. Diagnostic tests and correlograms suggest that including three lags of the dependent variable is sufficient to capture this dependency, resulting in a third-order autoregressive model, AR(3). Furthermore, the means of the log-differenced series do not differ significantly by country, ${ }^{11}$ and this allows us to treat the data as a pooled panel (but note

\footnotetext{
${ }^{11}$ Judging by either a Hausman test or an $F$-test of inconsistency between the within-estimator and the pooled-estimator $(p>.9)$.
} 
that the supporting information also includes country-specific replications of our model). Turning to the disturbances again, some autoregressive conditional heteroskedasticity $(\mathrm{ARCH})$ remains in our model (Engle, 1982). We address this issue by using a Whitetype generally heteroskedasticity consistent (HC) covariance matrix when calculating the standard errors (White, 1980). As a robustness check, this appendix also includes countryspecific $\operatorname{GARCH}(1,1)$ models, as an alternative approach to address the heteroskedasticity (Bollerslev, 1986). ${ }^{12}$

\section{Robustness Checks}

In this section we report a number of robustness checks. While there are strong theoretical (and empirical) reasons to expect the events in our data mainly to have effects on the same day as they take place, with a possible delayed effect on the next day, it is worth checking whether alternative windows would yield notably different results. Thus, we re-estimate our main model while expanding the event window one day in each direction, testing a window that starts the day before the event $[-1,1]$, and one that lasts two days after $[0,2]$. Summary information about these models is reported in table S3 and the results are shown in figure S1. The key point to notice, is that there is very little variation in the estimates across the windows (with the exception of negative decisions, for which we at any rate fail to find a significant effect in any model given the large uncertainty surrounding the estimates.) Most notably, the large effects at the European level are very robust to the selection of alternative windows. ${ }^{13}$

Another question is whether our approach to deal with auto-regressive heteroskedasticity (i.e. using $\mathrm{HC}$ covariance matrices) is appropriate, or whether GARCH models would yield notably different results. To assess this issue, we estimate our model separately for each country, both as a linear OLS model and as a GARCH model. Diagnostics

\footnotetext{
${ }^{12}$ Traditionally, non-spherical errors have been considered only to undermine the standard errors of a linear model (while also being a possible indication specification error). Corrected standard errors have thus been a common solution, based on the assumption of appropriate model specification. Recently, King and Roberts (2014) have argued against this approach, based on the view that misspecification is very likely in the presence of non-spherical errors. We thus present GARCH models to assess whether modeling the heteroskedasticity makes a difference for our substantive results.

${ }^{13}$ It should also be noted that, in order to draw reliable conclusions, our analysis focuses on short-term reactions than can be identified with reasonable confidence. In contrast, we do not seek to assess how long the effects of the events last, as these over time will blend with others, making it hard, if not impossible to distinguish between them. Nevertheless, it should be noted that the original series of bond spreads are integrated, and thus retain a perfect memory of previous shocks: Unless the effects are completely reversed outside of the windows we investigate, they will indeed have lasting impacts.
} 
Table S3: Summary of the Models Reported in Figure S1.

\begin{tabular}{lccc}
\hline & Model 7 & Model 1 & Model 8 \\
\hline Reported in Figure & 4 & $1 / 4$ & 4 \\
Model type & Pooled & Pooled & Pooled \\
AR $(l)$ & 3 & 3 & 3 \\
National events & Incl. & Incl. & Incl. \\
European events & Incl. & Incl. & Incl. \\
Quarter, Fixed Eff. & Incl. & Incl. & Incl. \\
No. of Parameters & 88 & 65 & 88 \\
Observations & 5185 & 5185 & 5185 \\
Event window & {$[-1,1]$} & {$[0,1]$} & {$[0,2]$} \\
HC cov. matrix & Yes & Yes & Yes \\
AR-test, $p$-value & 0.231 & 0.318 & 0.214 \\
\hline Note: AR-test refers to a weighted Ljung-Box-type portmanteau test for serial \\
correlation, using 8 lags (Fisher and Gallagher, 2012; Ljung and Box, 1978).
\end{tabular}

Figure S1: General Results Using Alternative Event Windows.

Negative National Signals

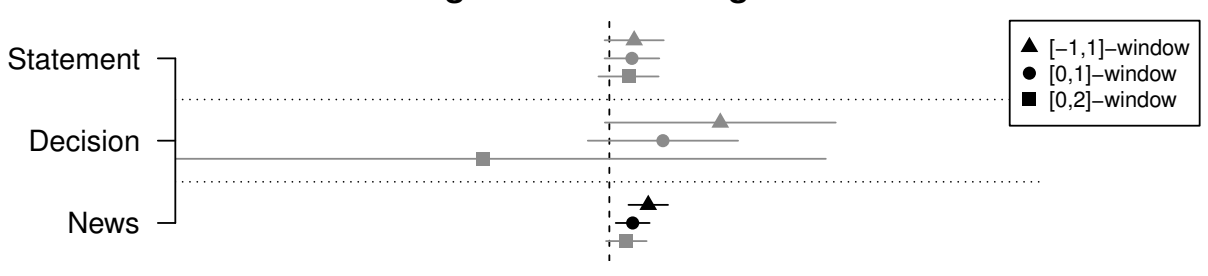

Positive National Signals

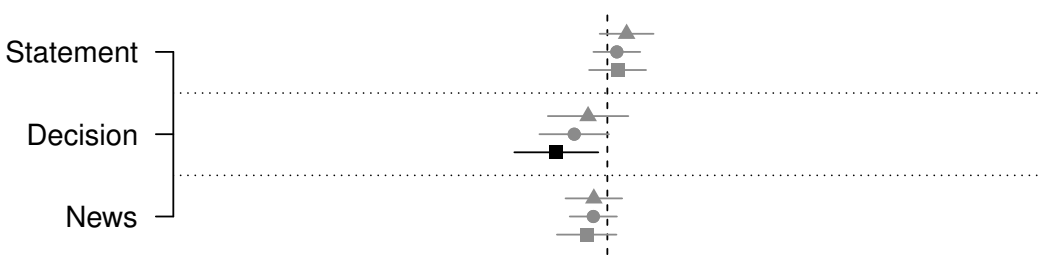

Positive European Signals

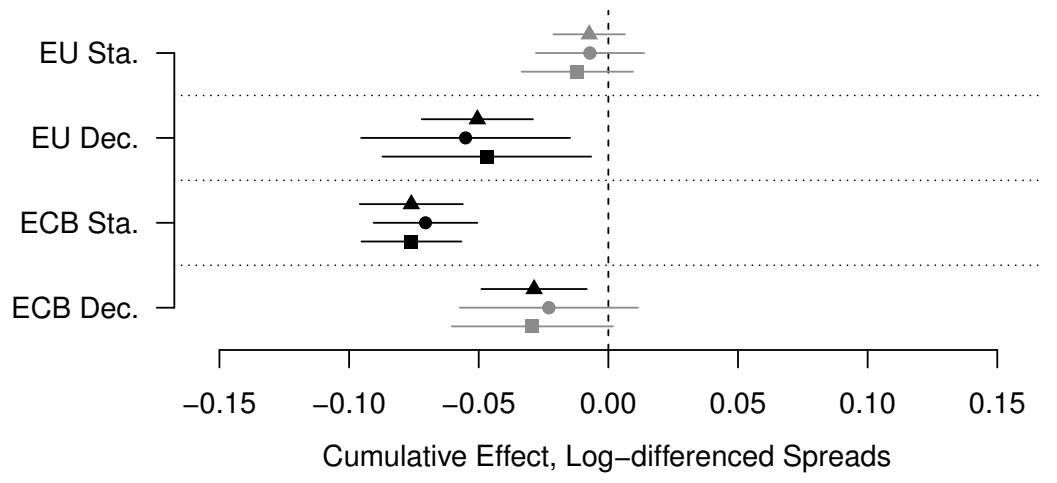

Note: The error bars give $95 \%$ confidence intervals; statistically significant estimates are shown in black, insignificant ones in gray. The standard errors are calculated using generally heteroskedasticity consistent covariance matrices. 
suggest that a GARCH $(1,1)$ model is sufficient to capture the heteroskedasticy, and the conditional variance of these models is thus given by:

$$
\sigma_{t}^{2}=\omega_{0}+\omega_{1} \varepsilon_{t-1}^{2}+\omega_{2} \sigma_{t-1}^{2}
$$

where $\varepsilon^{2}$ is an ARCH term, $\sigma^{2}$ is a GARCH term. Summary information for the ten models in question is reported in table S4, and the key effects are shown in figure S2 (the full sets of estimates for each model are also reported below). The key point to notice is that the OLS and GARCH models generally agree on the direction and magnitudes of the effects. There is no sign that an alternative modeling strategy would yield substantively different results.

Table S4: Summary of the Models Reported in Figure S2.

\begin{tabular}{|c|c|c|c|c|c|}
\hline & Model 9 & Model 10 & Model 11 & Model 12 & Model 13 \\
\hline Model type & OLS & OLS & OLS & OLS & OLS \\
\hline Country & Greece & Italy & Ireland & Portugal & Spain \\
\hline $\operatorname{AR}(l)$ & 3 & 3 & 3 & 3 & 3 \\
\hline Variance eq. $(p, q)$ & None & None & None & None & None \\
\hline National events & Incl. & Incl. & Incl. & Incl. & Incl. \\
\hline European events & Incl. & Incl. & Incl. & Incl. & Incl. \\
\hline Quarter, Fixed Eff. & Incl. & Incl. & Incl. & Incl. & Incl. \\
\hline No. of Parameters & 65 & 65 & 63 & 65 & 65 \\
\hline Observations & 1037 & 1037 & 1037 & 1037 & 1037 \\
\hline Event window & {$[0,1]$} & {$[0,1]$} & {$[0,1]$} & {$[0,1]$} & {$[0,1]$} \\
\hline AR-test, $p$-value & 0.943 & 0.541 & 0.543 & 0.678 & 0.522 \\
\hline ARCH-test, $p$-value & 0.711 & 0.000 & 0.038 & 0.000 & 0.001 \\
\hline \multirow[t]{2}{*}{ HC cov. matrix } & Yes & Yes & Yes & Yes & Yes \\
\hline & Model 14 & Model 15 & Model 16 & Model 17 & Model 18 \\
\hline Model type & GARCH & GARCH & GARCH & GARCH & GARCH \\
\hline Country & Greece & Italy & Ireland & Portugal & Spain \\
\hline $\operatorname{AR}(l)$ & 3 & 3 & 3 & 3 & 3 \\
\hline Variance eq. $(p, q)$ & 1,1 & 1,1 & 1,1 & 1,1 & 1,1 \\
\hline National events & Incl. & Incl. & Incl. & Incl. & Incl. \\
\hline European events & Incl. & Incl. & Incl. & Incl. & Incl. \\
\hline Quarter, Fixed Eff. & Incl. & Incl. & Incl. & Incl. & Incl. \\
\hline No. of Parameters & 68 & 68 & 66 & 68 & 68 \\
\hline Observations & 1037 & 1037 & 1037 & 1037 & 1037 \\
\hline Event window & {$[0,1]$} & {$[0,1]$} & {$[0,1]$} & {$[0,1]$} & {$[0,1]$} \\
\hline AR-test, $p$-value & 0.697 & 0.828 & 0.495 & 0.339 & 0.090 \\
\hline ARCH-test, $p$-value & 0.506 & 0.265 & 0.663 & 0.716 & 0.588 \\
\hline $\begin{array}{l}\text { Note: AR-test refers to } \\
\text { using } 8 \text { lags (Fisher and } \\
\text { tests are based on stand } \\
\text { ARCH test with } 8 \text { lags; } \\
\text { test by Li and Mak usin }\end{array}$ & lized residu & g-Box-typ & ortmantea & est for seri & $\begin{array}{l}\text { correlation, } \\
\text { models, the } \\
\text { Engle's LM } \\
\text { rsion of the }\end{array}$ \\
\hline
\end{tabular}


Figure S2: Results by Country Using OLS and GARCH Models.

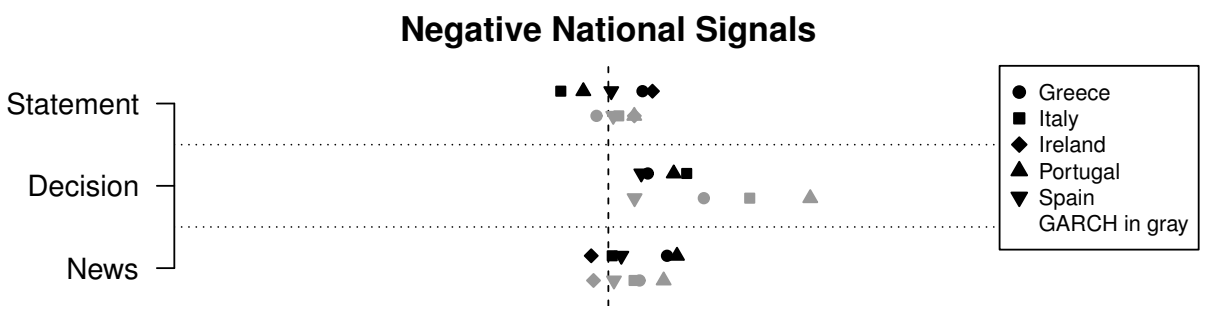

Positive National Signals

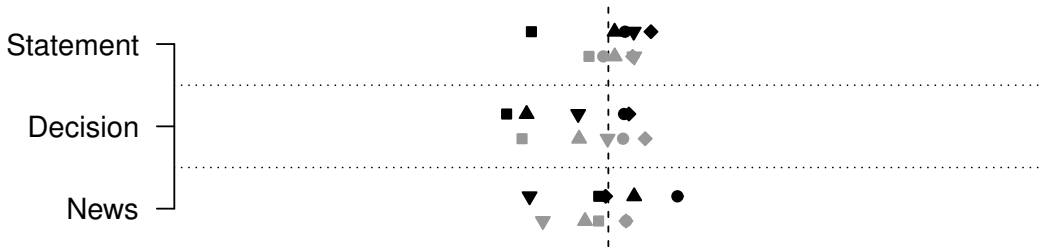

Positive European Signals

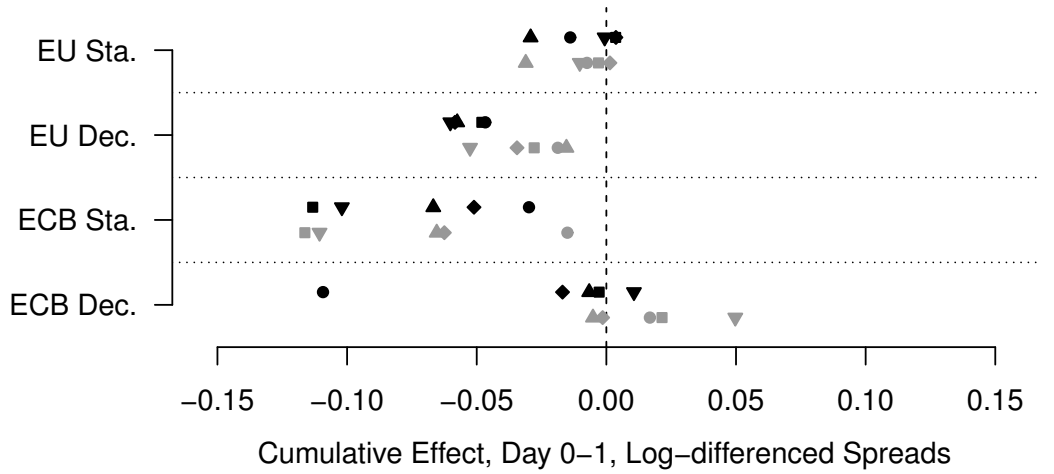

Note: AR(3)DL estimates are shown in black, AR(3)DL-GARCH(1,1) estimates are shown in gray. 


\section{Complete Results for All Models}

On the following pages, we report the complete sets of estimates for all models used in this study. The numbering of the models correspond to the numbering used in the summary tables reported above as well as those in main document. 
Table S5: AR(3)DL Panel Estimates (Model 1)

\begin{tabular}{|c|c|c|c|c|}
\hline & \multicolumn{2}{|l|}{$t$} & \multicolumn{2}{|c|}{$t-1$} \\
\hline & Estimate & Std. Error & Estimate & Std. Error \\
\hline Intercept & 0.004 & 0.003 & & \\
\hline Sta.Gov.Neg & 0.005 & 0.004 & 0.004 & 0.004 \\
\hline Dec.Gov.Neg & 0.004 & 0.005 & 0.016 & 0.014 \\
\hline NA.News.Neg & $0.006^{* * *}$ & 0.002 & 0.003 & 0.002 \\
\hline Sta.Gov.Pos & -0.001 & 0.003 & 0.005 & 0.003 \\
\hline Dec.Gov.Pos & -0.009 & 0.005 & -0.004 & 0.005 \\
\hline NA.News.Pos & -0.002 & 0.003 & -0.004 & 0.003 \\
\hline NA.Prot.Mix & 0.005 & 0.004 & 0.001 & 0.005 \\
\hline NA.Elec.Mix & 0.008 & 0.008 & 0.008 & 0.006 \\
\hline Sta.Ger.Neg & $0.006^{* * *}$ & 0.002 & 0.001 & 0.002 \\
\hline Sta.EU.Neg & 0.001 & 0.004 & $-0.017^{* * *}$ & 0.006 \\
\hline Int.ECB.Neg & -0.006 & 0.005 & -0.004 & 0.005 \\
\hline Sta.ECB.Neg & $0.020^{* * *}$ & 0.006 & -0.004 & 0.004 \\
\hline Sta.Ger.Pos & 0.000 & 0.003 & -0.007 & 0.004 \\
\hline Dec.Ger.Pos & -0.007 & 0.005 & $-0.032^{* * *}$ & 0.012 \\
\hline Sta.EU.Pos & -0.007 & 0.005 & -0.000 & 0.009 \\
\hline Dec.EU.Pos & $-0.040^{* * *}$ & 0.011 & -0.015 & 0.012 \\
\hline Int.ECB.Pos & $0.031^{* * *}$ & 0.012 & $-0.076^{* * *}$ & 0.026 \\
\hline Sta.ECB.Pos & $-0.037^{* * *}$ & 0.008 & $-0.033^{* * *}$ & 0.006 \\
\hline Dec.ECB.Pos & $-0.020^{* *}$ & 0.009 & -0.003 & 0.016 \\
\hline Sta.Ger.Mix & $-0.005^{* *}$ & 0.002 & $0.005^{* *}$ & 0.002 \\
\hline Sta.EU.Mix & $-0.011^{* * *}$ & 0.004 & 0.005 & 0.005 \\
\hline Dec.EU.Mix & -0.004 & 0.006 & $0.010^{* *}$ & 0.004 \\
\hline Sta.ECB.Mix & 0.006 & 0.019 & $-0.019^{* *}$ & 0.010 \\
\hline 2009.Q2 & $-0.007^{* *}$ & 0.003 & & \\
\hline 2009.Q3 & $-0.008^{* *}$ & 0.003 & & \\
\hline 2009.Q4 & -0.003 & 0.003 & & \\
\hline 2010.Q1 & -0.001 & 0.004 & & \\
\hline 2010.Q2 & $0.014^{* * *}$ & 0.004 & & \\
\hline 2010.Q3 & -0.003 & 0.003 & & \\
\hline 2010.Q4 & -0.002 & 0.003 & & \\
\hline 2011.Q1 & -0.005 & 0.003 & & \\
\hline 2011.Q2 & -0.001 & 0.003 & & \\
\hline 2011.Q3 & -0.001 & 0.004 & & \\
\hline 2011.Q4 & 0.001 & 0.003 & & \\
\hline 2012.Q1 & $-0.009^{* *}$ & 0.004 & & \\
\hline 2012.Q2 & -0.003 & 0.003 & & \\
\hline 2012.Q3 & -0.003 & 0.003 & & \\
\hline 2012.Q4 & -0.004 & 0.003 & & \\
\hline$y_{t-1}$ & $0.208^{* * *}$ & 0.031 & & \\
\hline$y_{t-2}$ & $-0.063^{* * *}$ & 0.023 & & \\
\hline$y_{t-3}$ & $-0.072^{* * *}$ & 0.024 & & \\
\hline $\begin{array}{l}\text { Note: }{ }^{*} p< \\
\text { The events hav } \\
\text { The first quart } \\
\text { column, events } \\
\text { The standard } \\
\text { covariance mat }\end{array}$ & $\begin{array}{l}* * p<0.05 \\
\text { s }[0,1] \text { repres } \\
2009 \text { is bas } \\
\text { denoted: Fo } \\
\text { s are based }\end{array}$ & $\begin{array}{l}* * * p<0 \\
\text { ated in colu } \\
\text { category for } \\
\text { m.Actor.Dir } \\
\text { a generally }\end{array}$ & $\begin{array}{l}R^{2}=0.132 ; \\
2-3, \text { and } 4-5, \\
\text { fixed effects } \\
n, \text { cf. Table } \\
\text { eroskedastici }\end{array}$ & $\begin{array}{l}N=5185 . \\
\text { espectively. } \\
\text { In the first } \\
\mathrm{S} 1 \text { and } \mathrm{S} 2 . \\
\text { consistent }\end{array}$ \\
\hline
\end{tabular}


Table S6: AR(3)DL Panel Estimates, Low Capacity (Model 2)

\begin{tabular}{|c|c|c|c|c|}
\hline & \multicolumn{2}{|l|}{$t$} & \multicolumn{2}{|c|}{$t-1$} \\
\hline & Estimate & Std. Error & Estimate & Std. Error \\
\hline Intercept & $0.006^{*}$ & 0.003 & & \\
\hline Sta.Gov.Neg & 0.004 & 0.005 & 0.006 & 0.004 \\
\hline Dec.Gov.Neg & -0.000 & 0.007 & 0.014 & 0.020 \\
\hline NA.News.Neg & 0.005 & 0.003 & $0.006^{*}$ & 0.003 \\
\hline Sta.Gov.Pos & 0.001 & 0.004 & 0.006 & 0.004 \\
\hline Dec.Gov.Pos & -0.006 & 0.008 & -0.001 & 0.007 \\
\hline NA.News.Pos & $0.007^{* *}$ & 0.004 & 0.002 & 0.004 \\
\hline NA.Prot.Mix & 0.003 & 0.005 & 0.003 & 0.006 \\
\hline NA.Elec.Mix & 0.000 & 0.014 & $0.011^{* * *}$ & 0.004 \\
\hline Sta.Ger.Neg & $0.006^{* * *}$ & 0.002 & 0.001 & 0.002 \\
\hline Sta.EU.Neg & 0.005 & 0.004 & -0.004 & 0.003 \\
\hline Int.ECB.Neg & $-0.014^{* *}$ & 0.006 & 0.001 & 0.004 \\
\hline Sta.ECB.Neg & $0.009^{* *}$ & 0.004 & 0.004 & 0.005 \\
\hline Sta.Ger.Pos & 0.001 & 0.004 & -0.001 & 0.005 \\
\hline Dec.Ger.Pos & -0.006 & 0.006 & $-0.040^{* *}$ & 0.016 \\
\hline Sta.EU.Pos & -0.009 & 0.006 & -0.003 & 0.010 \\
\hline Dec.EU.Pos & $-0.034^{* *}$ & 0.015 & -0.021 & 0.016 \\
\hline Int.ECB.Pos & $0.037^{* * *}$ & 0.014 & $-0.084^{* *}$ & 0.037 \\
\hline Sta.ECB.Pos & $-0.021^{* * *}$ & 0.006 & $-0.027^{* * *}$ & 0.006 \\
\hline Dec.ECB.Pos & $-0.030^{* *}$ & 0.013 & -0.015 & 0.026 \\
\hline Sta.Ger.Mix & -0.003 & 0.003 & $0.006^{*}$ & 0.003 \\
\hline Sta.EU.Mix & -0.007 & 0.005 & 0.009 & 0.006 \\
\hline Dec.EU.Mix & -0.008 & 0.007 & 0.001 & 0.005 \\
\hline Sta.ECB.Mix & 0.015 & 0.015 & -0.008 & 0.006 \\
\hline 2009.Q2 & $-0.008^{* *}$ & 0.004 & & \\
\hline 2009.Q3 & $-0.011^{* * *}$ & 0.004 & & \\
\hline 2009.Q4 & -0.004 & 0.004 & & \\
\hline 2010.Q1 & -0.005 & 0.005 & & \\
\hline 2010.Q2 & $0.011^{* *}$ & 0.005 & & \\
\hline 2010.Q3 & -0.004 & 0.004 & & \\
\hline 2010.Q4 & -0.006 & 0.004 & & \\
\hline 2011.Q1 & -0.006 & 0.004 & & \\
\hline 2011.Q2 & -0.003 & 0.004 & & \\
\hline 2011.Q3 & -0.004 & 0.004 & & \\
\hline 2011.Q4 & -0.001 & 0.004 & & \\
\hline 2012.Q1 & $-0.011^{*}$ & 0.006 & & \\
\hline 2012.Q2 & $-0.007^{*}$ & 0.004 & & \\
\hline 2012.Q3 & $-0.008^{* *}$ & 0.004 & & \\
\hline 2012.Q4 & $-0.008^{*}$ & 0.004 & & \\
\hline$y_{t-1}$ & $0.198^{* * *}$ & 0.047 & & \\
\hline$y_{t-2}$ & -0.030 & 0.028 & & \\
\hline$y_{t-3}$ & $-0.082^{* *}$ & 0.037 & & \\
\hline $\begin{array}{l}\text { Note: }{ }^{*} p<0 \\
\text { events have lag } \\
\text { first quarter of } \\
\text { events are den } \\
\text { dard errors are } \\
\text { matrix. }\end{array}$ & $\begin{array}{l}\text { k* } p<0.05, \\
, 1] \text { represente } \\
9 \text { is base categ } \\
\text { l: Form. Actor } \\
\text { sed on a gener }\end{array}$ & $\begin{array}{l}* p<0.01 ; \\
\text { in columns } \\
\text { ry for the fix } \\
\text { Direction, cf } \\
\text { ly heteroske }\end{array}$ & $\begin{array}{l}=0.143 ; N \\
\text { and } 4-5, \text { resp } \\
\text { effects. In the } \\
\text { ables } 2 \text { and } \\
\text { icity consiste }\end{array}$ & $\begin{array}{l}3111 . \text { The } \\
\text { tively. The } \\
\text { rst column, } \\
\text { The stan- } \\
\text { covariance }\end{array}$ \\
\hline
\end{tabular}


Table S7: AR(3)DL Panel Estimates, Med. Capacity (Model 3)

\begin{tabular}{|c|c|c|c|c|}
\hline & \multicolumn{2}{|l|}{$t$} & \multicolumn{2}{|c|}{$t-1$} \\
\hline & Estimate & Std. Error & Estimate & Std. Error \\
\hline Intercept & 0.001 & 0.004 & & \\
\hline Sta.Gov.Neg & 0.007 & 0.013 & -0.012 & 0.012 \\
\hline Dec.Gov.Neg & 0.010 & 0.007 & 0.018 & 0.020 \\
\hline NA.News.Neg & $0.007^{* *}$ & 0.003 & -0.002 & 0.003 \\
\hline Sta.Gov.Pos & -0.004 & 0.006 & 0.003 & 0.006 \\
\hline Dec.Gov.Pos & -0.010 & 0.007 & -0.012 & 0.007 \\
\hline NA.News.Pos & $-0.012^{* *}$ & 0.005 & $-0.010^{*}$ & 0.005 \\
\hline NA.Prot.Mix & $0.013^{* *}$ & 0.006 & -0.005 & 0.007 \\
\hline NA.Elec.Mix & 0.013 & 0.009 & 0.005 & 0.011 \\
\hline Sta.Ger.Neg & $0.006^{* *}$ & 0.003 & 0.000 & 0.003 \\
\hline Sta.EU.Neg & 0.002 & 0.010 & $-0.034^{* * *}$ & 0.010 \\
\hline Int.ECB.Neg & 0.004 & 0.007 & -0.011 & 0.011 \\
\hline Sta.ECB.Neg & $0.040^{* * *}$ & 0.006 & $-0.014^{*}$ & 0.008 \\
\hline Sta.Ger.Pos & -0.001 & 0.005 & $-0.016^{* *}$ & 0.008 \\
\hline Dec.Ger.Pos & -0.009 & 0.007 & -0.022 & 0.016 \\
\hline Sta.EU.Pos & -0.002 & 0.009 & 0.002 & 0.018 \\
\hline Dec.EU.Pos & $-0.046^{* * *}$ & 0.014 & -0.007 & 0.015 \\
\hline Int.ECB.Pos & 0.024 & 0.020 & $-0.058^{*}$ & 0.032 \\
\hline Sta.ECB.Pos & $-0.061^{* * *}$ & 0.014 & $-0.049^{* * *}$ & 0.007 \\
\hline Dec.ECB.Pos & -0.007 & 0.012 & 0.012 & 0.010 \\
\hline Sta.Ger.Mix & $-0.008^{* *}$ & 0.004 & 0.004 & 0.004 \\
\hline Sta.EU.Mix & $-0.018^{* * *}$ & 0.007 & -0.003 & 0.007 \\
\hline Dec.EU.Mix & 0.001 & 0.011 & $0.023^{* * *}$ & 0.005 \\
\hline Sta.ECB.Mix & -0.004 & 0.044 & $-0.037^{*}$ & 0.020 \\
\hline 2009.Q2 & -0.005 & 0.006 & & \\
\hline 2009.Q3 & -0.004 & 0.006 & & \\
\hline 2009.Q4 & -0.002 & 0.006 & & \\
\hline 2010.Q1 & 0.004 & 0.006 & & \\
\hline 2010.Q2 & $0.018^{* * *}$ & 0.006 & & \\
\hline 2010.Q3 & 0.001 & 0.005 & & \\
\hline 2010.Q4 & 0.003 & 0.005 & & \\
\hline 2011.Q1 & -0.002 & 0.005 & & \\
\hline 2011.Q2 & 0.004 & 0.005 & & \\
\hline 2011.Q3 & 0.007 & 0.006 & & \\
\hline 2011.Q4 & 0.004 & 0.006 & & \\
\hline 2012.Q1 & -0.004 & 0.005 & & \\
\hline 2012.Q2 & 0.006 & 0.005 & & \\
\hline 2012.Q3 & 0.005 & 0.005 & & \\
\hline 2012.Q4 & 0.003 & 0.005 & & \\
\hline$y_{t-1}$ & $0.214^{* * *}$ & 0.030 & & \\
\hline$y_{t-2}$ & $-0.114^{* * *}$ & 0.030 & & \\
\hline$y_{t-3}$ & $-0.059^{* *}$ & 0.024 & & \\
\hline $\begin{array}{l}\text { Note: }{ }^{*} p<0 \\
\text { events have la } \\
\text { first quarter of } \\
\text { events are den } \\
\text { dard errors are } \\
\text { matrix. }\end{array}$ & $\begin{array}{l}* p<0.05, * \\
1] \text { represented } \\
9 \text { is base categ } \\
: \text { Form.Actor } \\
\text { ed on a gener }\end{array}$ & $\begin{array}{l}{ }^{*} p<0.01 \\
\text { in columns } \\
\text { ry for the fix } \\
\text { Direction, cf } \\
\text { lly heteroske }\end{array}$ & $\begin{array}{l}=0.144 ; N= \\
\text { and } 4-5, \text { resp } \\
\text { ffects. In the } \\
\text { ables } 2 \text { and } 3 \\
\text { icity consiste }\end{array}$ & $\begin{array}{l}2074 . \text { The } \\
\text { tively. The } \\
\text { rst column, } \\
\text { The stan- } \\
\text { covariance }\end{array}$ \\
\hline
\end{tabular}


Table S8: Estimates for the Placebo Test with a [-1,1]-Window (Model 4)

\begin{tabular}{|c|c|c|c|c|c|c|}
\hline & \multicolumn{2}{|c|}{$t+1$} & \multicolumn{2}{|l|}{$t$} & \multicolumn{2}{|c|}{$t-1$} \\
\hline & Estimate & Std. Error & Estimate & Std. Error & Estimate & Std. Error \\
\hline Intercept & & & 0.003 & 0.003 & & \\
\hline Weak.Gov.Neg & 0.003 & 0.003 & 0.004 & 0.004 & 0.002 & 0.004 \\
\hline Strong.Gov.Neg & 0.023 & 0.017 & 0.005 & 0.005 & 0.015 & 0.013 \\
\hline NA.News.Neg & $0.007^{* * *}$ & 0.002 & $0.006^{* * *}$ & 0.002 & 0.002 & 0.002 \\
\hline Weak.Gov.Pos & $0.005^{*}$ & 0.003 & -0.002 & 0.003 & 0.004 & 0.003 \\
\hline Strong.Gov.Pos & 0.006 & 0.005 & -0.009 & 0.005 & -0.004 & 0.005 \\
\hline NA.News.Pos & 0.001 & 0.003 & -0.002 & 0.003 & -0.004 & 0.003 \\
\hline NA.Prot.Mix & -0.005 & 0.004 & 0.006 & 0.004 & 0.000 & 0.004 \\
\hline NA.Elec.Mix & -0.004 & 0.006 & 0.007 & 0.008 & 0.007 & 0.006 \\
\hline Sta.Ger.Neg & -0.001 & 0.002 & $0.007^{* * *}$ & 0.002 & 0.001 & 0.002 \\
\hline Sta.EU.Neg & -0.004 & 0.010 & 0.001 & 0.003 & $-0.015^{* *}$ & 0.006 \\
\hline Int.ECB.Neg & $-0.026^{* * *}$ & 0.008 & -0.005 & 0.005 & -0.006 & 0.005 \\
\hline Sta.ECB.Neg & $-0.010^{* *}$ & 0.004 & $0.018^{* * *}$ & 0.006 & -0.001 & 0.005 \\
\hline Sta.Ger.Pos & 0.003 & 0.004 & 0.001 & 0.003 & -0.006 & 0.004 \\
\hline Dec.Ger.Pos & -0.004 & 0.005 & -0.006 & 0.005 & $-0.032^{* * *}$ & 0.012 \\
\hline Sta.EU.Pos & 0.000 & 0.004 & -0.008 & 0.006 & -0.000 & 0.009 \\
\hline Dec.EU.Pos & 0.005 & 0.005 & $-0.041^{* * *}$ & 0.011 & -0.017 & 0.011 \\
\hline Int.ECB.Pos & $0.038^{* * *}$ & 0.012 & $0.035^{* * *}$ & 0.012 & $-0.074^{* * *}$ & 0.026 \\
\hline Sta.ECB.Pos & -0.005 & 0.006 & $-0.037^{* * *}$ & 0.008 & $-0.034^{* * *}$ & 0.006 \\
\hline Dec.ECB.Pos & -0.006 & 0.004 & $-0.020^{* *}$ & 0.010 & -0.003 & 0.016 \\
\hline Sta.Ger.Mix & 0.001 & 0.002 & $-0.005^{* *}$ & 0.002 & $0.006^{* *}$ & 0.002 \\
\hline Sta.EU.Mix & 0.002 & 0.004 & $-0.011^{* * *}$ & 0.004 & 0.004 & 0.005 \\
\hline Dec.EU.Mix & $-0.016^{* * *}$ & 0.004 & -0.005 & 0.006 & $0.010^{* *}$ & 0.004 \\
\hline Sta.ECB.Mix & -0.007 & 0.010 & 0.004 & 0.018 & $-0.021^{* *}$ & 0.010 \\
\hline Dec.EU.Pla & $-0.013^{* *}$ & 0.006 & -0.007 & 0.006 & $0.016^{* * *}$ & 0.006 \\
\hline 2009.Q2 & & & $-0.006^{*}$ & 0.003 & & \\
\hline 2009.Q3 & & & $-0.007^{* *}$ & 0.003 & & \\
\hline 2009.Q4 & & & -0.002 & 0.004 & & \\
\hline 2010.Q1 & & & -0.001 & 0.004 & & \\
\hline 2010.Q2 & & & $0.014^{* * *}$ & 0.004 & & \\
\hline 2010.Q3 & & & -0.002 & 0.003 & & \\
\hline 2010.Q4 & & & -0.001 & 0.003 & & \\
\hline 2011.Q1 & & & -0.004 & 0.003 & & \\
\hline 2011.Q2 & & & 0.001 & 0.003 & & \\
\hline 2011.Q3 & & & 0.000 & 0.004 & & \\
\hline 2011.Q4 & & & 0.001 & 0.003 & & \\
\hline 2012.Q1 & & & $-0.007^{*}$ & 0.004 & & \\
\hline 2012.Q2 & & & -0.002 & 0.003 & & \\
\hline 2012.Q3 & & & -0.002 & 0.003 & & \\
\hline 2012.Q4 & & & -0.003 & 0.003 & & \\
\hline$y_{t-1}$ & & & $0.200^{* * *}$ & 0.031 & & \\
\hline$y_{t-2}$ & & & $-0.063^{* * *}$ & 0.023 & & \\
\hline$y_{t-3}$ & & & $-0.070^{* * *}$ & 0.024 & & \\
\hline
\end{tabular}

Note: ${ }^{*} p<0.1,{ }^{* *} p<0.05,{ }^{* * *} p<0.01 ; R^{2}=0.144 ; N=5185$. The events have lags [-1,0,1] represented in columns 2-3, 4-5, and 6-7, respectively. The first quarter of 2009 is base category for the fixed effects. In the first column, events are denoted: Form.Actor.Direction, cf. Tables 2 and 3 . The standard errors are based on a generally heteroskedasticity consistent covariance matrix. 
Table S9: Placebo Test with a [0,1]-Window (Model 5)

\begin{tabular}{|c|c|c|c|c|}
\hline & \multicolumn{2}{|l|}{$t$} & \multicolumn{2}{|c|}{$t-1$} \\
\hline & Estimate & Std. Error & Estimate & Std. Error \\
\hline Intercept & 0.004 & 0.003 & & \\
\hline Weak.Gov.Neg & 0.004 & 0.004 & 0.004 & 0.004 \\
\hline Strong.Gov.Neg & 0.004 & 0.005 & 0.016 & 0.014 \\
\hline NA.News.Neg & $0.006^{* * *}$ & 0.002 & 0.003 & 0.002 \\
\hline Weak.Gov.Pos & -0.001 & 0.003 & 0.005 & 0.003 \\
\hline Strong.Gov.Pos & -0.008 & 0.005 & -0.004 & 0.005 \\
\hline NA.News.Pos & -0.002 & 0.003 & -0.004 & 0.003 \\
\hline NA.Prot.Mix & 0.006 & 0.004 & 0.001 & 0.004 \\
\hline NA.Elec.Mix & 0.007 & 0.008 & 0.008 & 0.006 \\
\hline Sta.Ger.Neg & $0.006^{* * *}$ & 0.002 & 0.001 & 0.002 \\
\hline Sta.EU.Neg & 0.002 & 0.004 & $-0.017^{* * *}$ & 0.006 \\
\hline Int.ECB.Neg & -0.006 & 0.005 & -0.004 & 0.005 \\
\hline Sta.ECB.Neg & $0.020^{* * *}$ & 0.006 & -0.004 & 0.004 \\
\hline Sta.Ger.Pos & 0.001 & 0.003 & -0.007 & 0.004 \\
\hline Dec.Ger.Pos & -0.007 & 0.005 & $-0.032^{* * *}$ & 0.012 \\
\hline Sta.EU.Pos & -0.007 & 0.005 & 0.000 & 0.009 \\
\hline Dec.EU.Pos & $-0.040^{* * *}$ & 0.011 & -0.015 & 0.012 \\
\hline Int.ECB.Pos & $0.031^{* * *}$ & 0.012 & $-0.076^{* * *}$ & 0.026 \\
\hline Sta.ECB.Pos & $-0.037^{* * *}$ & 0.008 & $-0.033^{* * *}$ & 0.006 \\
\hline Dec.ECB.Pos & $-0.020^{* *}$ & 0.009 & -0.003 & 0.016 \\
\hline Sta.Ger.Mix & $-0.005^{* *}$ & 0.002 & $0.005^{* *}$ & 0.002 \\
\hline Sta.EU.Mix & $-0.011^{* *}$ & 0.004 & 0.005 & 0.005 \\
\hline Dec.EU.Mix & -0.004 & 0.006 & $0.010^{* *}$ & 0.004 \\
\hline Sta.ECB.Mix & 0.006 & 0.019 & $-0.019^{* *}$ & 0.010 \\
\hline Dec.EU.Pla & -0.007 & 0.006 & $0.016^{* * *}$ & 0.006 \\
\hline 2009.Q2 & $-0.007^{* *}$ & 0.003 & & \\
\hline 2009.Q3 & $-0.008^{* *}$ & 0.003 & & \\
\hline 2009.Q4 & -0.003 & 0.003 & & \\
\hline 2010.Q1 & -0.001 & 0.004 & & \\
\hline 2010.Q2 & $0.014^{* * *}$ & 0.004 & & \\
\hline 2010.Q3 & -0.002 & 0.003 & & \\
\hline 2010.Q4 & -0.002 & 0.003 & & \\
\hline 2011.Q1 & -0.004 & 0.003 & & \\
\hline 2011.Q2 & -0.000 & 0.003 & & \\
\hline 2011.Q3 & -0.001 & 0.004 & & \\
\hline 2011.Q4 & 0.001 & 0.003 & & \\
\hline 2012.Q1 & $-0.009^{* *}$ & 0.004 & & \\
\hline 2012.Q2 & -0.003 & 0.003 & & \\
\hline 2012.Q3 & -0.003 & 0.003 & & \\
\hline 2012.Q4 & -0.004 & 0.003 & & \\
\hline$y_{t-1}$ & $0.208^{* * *}$ & 0.031 & & \\
\hline$y_{t-2}$ & $-0.062^{* * *}$ & 0.023 & & \\
\hline$y_{t-3}$ & $-0.072^{* * *}$ & 0.024 & & \\
\hline $\begin{array}{l}\text { Note: }{ }^{*} p<0.1 \\
\text { events have lags } \\
\text { first quarter of } 20 \\
\text { events are denote } \\
\text { errors are based }\end{array}$ & $\begin{array}{l}p<0.05, \\
\text { ] represented } \\
\text { is base categc } \\
\text { Form.Actor.D } \\
\text { generally het }\end{array}$ & $\begin{array}{l}p<0.01 \\
\text { columns } 2 \\
\text { for the fix } \\
\text { ection, cf. }\end{array}$ & $\begin{array}{l}=0.134 ; N= \\
\text { and } 4-5, \text { respe } \\
\text { ffects. In the } \\
\text { es } 2 \text { and } 3 . \\
\text { asistent covari }\end{array}$ & $\begin{array}{l}5185 . \text { The } \\
\text { ively. The } \\
\text { cst column, } \\
\text { e standard } \\
\text { nce matrix. }\end{array}$ \\
\hline
\end{tabular}


Table S10: Estimates for the Placebo Test with a [0,2]-Window (Model 6)

\begin{tabular}{|c|c|c|c|c|c|c|}
\hline & \multicolumn{2}{|l|}{$t$} & \multicolumn{2}{|c|}{$t-1$} & \multicolumn{2}{|c|}{$t-2$} \\
\hline & Estimate & Std. Error & Estimate & Std. Error & Estimate & Std. Error \\
\hline Intercept & 0.003 & 0.003 & & & & \\
\hline Weak.Gov.Neg & 0.004 & 0.004 & 0.004 & 0.004 & -0.001 & 0.003 \\
\hline Strong.Gov.Neg & 0.003 & 0.005 & 0.015 & 0.014 & -0.067 & 0.065 \\
\hline NA.News.Neg & $0.007^{* * *}$ & 0.002 & 0.003 & 0.002 & -0.003 & 0.002 \\
\hline Weak.Gov.Pos & -0.001 & 0.003 & $0.006^{*}$ & 0.004 & -0.001 & 0.003 \\
\hline Strong.Gov.Pos & -0.008 & 0.006 & -0.004 & 0.005 & -0.007 & 0.006 \\
\hline NA.News.Pos & -0.002 & 0.003 & -0.004 & 0.003 & -0.002 & 0.004 \\
\hline NA.Prot.Mix & $0.007^{*}$ & 0.004 & 0.002 & 0.005 & 0.004 & 0.005 \\
\hline NA.Elec.Mix & 0.007 & 0.008 & 0.006 & 0.006 & 0.002 & 0.007 \\
\hline Sta.Ger.Neg & $0.006^{* * *}$ & 0.002 & 0.002 & 0.002 & 0.003 & 0.002 \\
\hline Sta.EU.Neg & 0.004 & 0.004 & $-0.017^{* *}$ & 0.006 & 0.008 & 0.007 \\
\hline Int.ECB.Neg & -0.006 & 0.005 & -0.002 & 0.005 & 0.004 & 0.009 \\
\hline Sta.ECB.Neg & $0.020^{* * *}$ & 0.006 & -0.002 & 0.004 & $0.020^{* * *}$ & 0.006 \\
\hline Sta.Ger.Pos & 0.003 & 0.003 & -0.006 & 0.004 & -0.004 & 0.003 \\
\hline Dec.Ger.Pos & -0.006 & 0.005 & $-0.029^{* *}$ & 0.012 & $0.017^{* * *}$ & 0.006 \\
\hline Sta.EU.Pos & -0.008 & 0.006 & -0.000 & 0.009 & -0.004 & 0.005 \\
\hline Dec.EU.Pos & $-0.041^{* * *}$ & 0.011 & -0.018 & 0.012 & $0.013^{* *}$ & 0.005 \\
\hline Int.ECB.Pos & $0.031^{* * *}$ & 0.012 & $-0.075^{* * *}$ & 0.026 & $0.016^{*}$ & 0.009 \\
\hline Sta.ECB.Pos & $-0.043^{* * *}$ & 0.008 & $-0.033^{* * *}$ & 0.006 & 0.001 & 0.007 \\
\hline Dec.ECB.Pos & $-0.019^{* *}$ & 0.009 & -0.006 & 0.014 & -0.004 & 0.008 \\
\hline Sta.Ger.Mix & $-0.004^{*}$ & 0.002 & $0.005^{* *}$ & 0.002 & 0.003 & 0.002 \\
\hline Sta.EU.Mix & $-0.010^{* *}$ & 0.004 & 0.005 & 0.005 & -0.005 & 0.004 \\
\hline Dec.EU.Mix & -0.004 & 0.006 & $0.007^{*}$ & 0.004 & -0.001 & 0.005 \\
\hline Sta.ECB.Mix & 0.008 & 0.018 & $-0.020^{*}$ & 0.010 & $-0.043^{* *}$ & 0.020 \\
\hline Dec.EU.Pla & -0.007 & 0.006 & $0.016^{* * *}$ & 0.006 & $-0.008^{* *}$ & 0.004 \\
\hline 2009.Q2 & $-0.007^{* *}$ & 0.003 & & & & \\
\hline 2009.Q3 & $-0.008^{* *}$ & 0.003 & & & & \\
\hline 2009.Q4 & -0.003 & 0.003 & & & & \\
\hline 2010.Q1 & -0.001 & 0.004 & & & & \\
\hline 2010.Q2 & $0.013^{* * *}$ & 0.004 & & & & \\
\hline 2010.Q3 & -0.001 & 0.003 & & & & \\
\hline 2010.Q4 & -0.001 & 0.003 & & & & \\
\hline 2011.Q1 & -0.004 & 0.003 & & & & \\
\hline 2011.Q2 & -0.001 & 0.003 & & & & \\
\hline 2011.Q3 & -0.000 & 0.004 & & & & \\
\hline 2011.Q4 & 0.001 & 0.003 & & & & \\
\hline 2012.Q1 & $-0.008^{* *}$ & 0.004 & & & & \\
\hline 2012.Q2 & -0.003 & 0.003 & & & & \\
\hline 2012.Q3 & -0.004 & 0.003 & & & & \\
\hline 2012.Q4 & -0.004 & 0.003 & & & & \\
\hline$y_{t-1}$ & $0.218^{* * *}$ & 0.033 & & & & \\
\hline$y_{t-2}$ & $-0.063^{* * *}$ & 0.024 & & & & \\
\hline$y_{t-3}$ & $-0.072^{* * *}$ & 0.022 & & & & \\
\hline $\begin{array}{l}\text { Note: }{ }^{*} p<0 . \\
\text { represented in } \mathrm{cc} \\
\text { fixed effects. In }\end{array}$ & $p<<0.05$ & $<0$. & $i^{2}=0.147$ & $=5185$. & events hav & $\begin{array}{l}\text { lags }[0,1,2] \\
\text { rory for the } \\
\text { and } 3 \text {. The }\end{array}$ \\
\hline
\end{tabular}


Table S11: Estimates for the AR(3)DL Panel Model with a [-1,1]-Window (Model 7)

\begin{tabular}{|c|c|c|c|c|c|c|}
\hline & \multicolumn{2}{|c|}{$t+1$} & \multicolumn{2}{|l|}{$t$} & \multicolumn{2}{|c|}{$t-1$} \\
\hline & Estimate & Std. Error & Estimate & Std. Error & Estimate & Std. Error \\
\hline Intercept & & & 0.002 & 0.003 & & \\
\hline Sta.Gov.Neg & 0.003 & 0.004 & 0.004 & 0.004 & 0.003 & 0.004 \\
\hline Dec.Gov.Neg & 0.023 & 0.017 & 0.004 & 0.005 & 0.015 & 0.013 \\
\hline NA.News.Neg & $0.007^{* * *}$ & 0.002 & $0.006^{* * *}$ & 0.002 & 0.002 & 0.002 \\
\hline Sta.Gov.Pos & $0.005^{*}$ & 0.003 & -0.002 & 0.003 & 0.004 & 0.003 \\
\hline Dec.Gov.Pos & 0.006 & 0.005 & -0.009 & 0.005 & -0.005 & 0.005 \\
\hline NA.News.Pos & 0.001 & 0.003 & -0.002 & 0.003 & -0.004 & 0.003 \\
\hline NA.Prot.Mix & -0.005 & 0.004 & 0.005 & 0.004 & 0.000 & 0.004 \\
\hline NA.Elec.Mix & -0.005 & 0.006 & 0.008 & 0.008 & 0.007 & 0.006 \\
\hline Sta.Ger.Neg & -0.001 & 0.002 & $0.007^{* * *}$ & 0.002 & 0.001 & 0.002 \\
\hline Sta.EU.Neg & -0.004 & 0.010 & 0.001 & 0.003 & $-0.015^{* *}$ & 0.006 \\
\hline Int.ECB.Neg & $-0.026^{* * *}$ & 0.008 & -0.005 & 0.005 & -0.006 & 0.005 \\
\hline Sta.ECB.Neg & $-0.010^{* *}$ & 0.004 & $0.018^{* * *}$ & 0.006 & -0.001 & 0.005 \\
\hline Sta.Ger.Pos & 0.003 & 0.004 & 0.001 & 0.003 & -0.005 & 0.004 \\
\hline Dec.Ger.Pos & -0.003 & 0.005 & -0.006 & 0.005 & $-0.032^{* * *}$ & 0.012 \\
\hline Sta.EU.Pos & 0.000 & 0.004 & -0.008 & 0.006 & -0.000 & 0.009 \\
\hline Dec.EU.Pos & 0.007 & 0.005 & $-0.040^{* * *}$ & 0.011 & -0.017 & 0.011 \\
\hline Int.ECB.Pos & $0.038^{* * *}$ & 0.012 & $0.035^{* * *}$ & 0.012 & $-0.074^{* * *}$ & 0.026 \\
\hline Sta.ECB.Pos & -0.005 & 0.005 & $-0.037^{* * *}$ & 0.008 & $-0.034^{* * *}$ & 0.006 \\
\hline Dec.ECB.Pos & -0.006 & 0.004 & $-0.020^{* *}$ & 0.010 & -0.003 & 0.016 \\
\hline Sta.Ger.Mix & 0.001 & 0.002 & $-0.006^{* *}$ & 0.002 & $0.006^{* *}$ & 0.002 \\
\hline Sta.EU.Mix & 0.002 & 0.004 & $-0.011^{* * *}$ & 0.004 & 0.004 & 0.005 \\
\hline Dec.EU.Mix & $-0.016^{* * *}$ & 0.004 & -0.004 & 0.006 & $0.010^{* *}$ & 0.004 \\
\hline Sta.ECB.Mix & -0.007 & 0.010 & 0.004 & 0.018 & $-0.022^{* *}$ & 0.010 \\
\hline 2009.Q2 & & & $-0.006^{*}$ & 0.003 & & \\
\hline 2009.Q3 & & & $-0.007^{* *}$ & 0.003 & & \\
\hline 2009.Q4 & & & -0.002 & 0.003 & & \\
\hline 2010.Q1 & & & -0.001 & 0.004 & & \\
\hline 2010.Q2 & & & $0.014^{* * *}$ & 0.004 & & \\
\hline 2010.Q3 & & & -0.002 & 0.003 & & \\
\hline 2010.Q4 & & & -0.001 & 0.003 & & \\
\hline 2011.Q1 & & & -0.004 & 0.003 & & \\
\hline 2011.Q2 & & & 0.001 & 0.003 & & \\
\hline 2011.Q3 & & & 0.000 & 0.004 & & \\
\hline 2011.Q4 & & & 0.001 & 0.003 & & \\
\hline 2012.Q1 & & & $-0.007^{*}$ & 0.004 & & \\
\hline 2012.Q2 & & & -0.002 & 0.003 & & \\
\hline 2012.Q3 & & & -0.002 & 0.003 & & \\
\hline 2012.Q4 & & & -0.003 & 0.003 & & \\
\hline$y_{t-1}$ & & & $0.201^{* * *}$ & 0.031 & & \\
\hline$y_{t-2}$ & & & $-0.065^{* * *}$ & 0.023 & & \\
\hline$y_{t-3}$ & & & $-0.072^{* * *}$ & 0.024 & & \\
\hline
\end{tabular}

Note: ${ }^{*} p<0.1,{ }^{* *} p<0.05,{ }^{* * *} p<0.01 ; R^{2}=0.142 ; N=5185$. The events have lags $[-1,0,1]$ represented in columns 2-3, 4-5, and 6-7, respectively. The first quarter of 2009 is base category for the fixed effects. In the first column, events are denoted: Form.Actor.Direction, cf. Tables 2 and 3 . The standard errors are based on a generally heteroskedasticity consistent covariance matrix. 
Table S12: Estimates for the AR(3)DL Panel Model with a [0,2]-Window (Model 8)

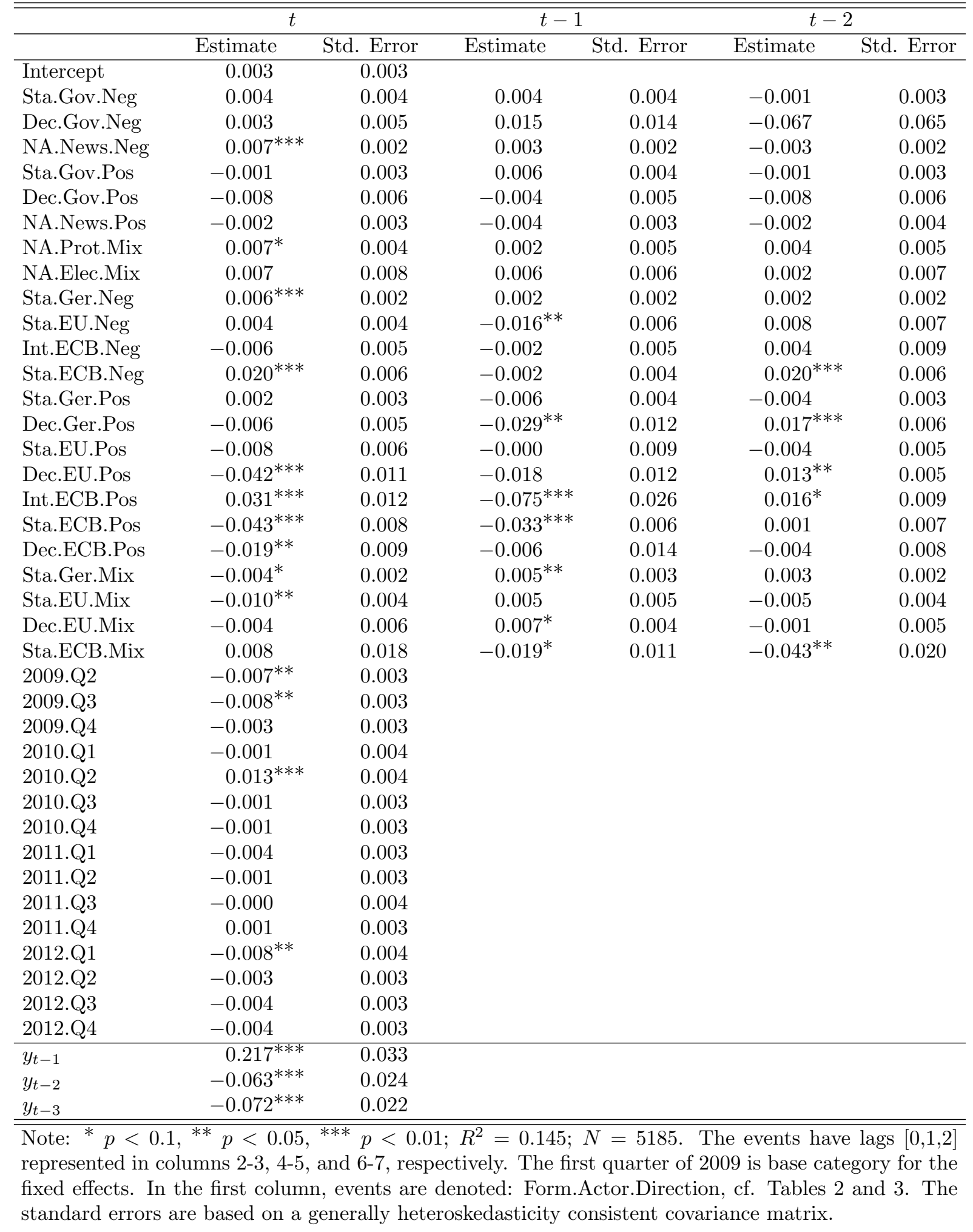


Table S13: AR(3)DL Estimates for Greece (Model 9)

\begin{tabular}{|c|c|c|c|c|}
\hline & \multicolumn{2}{|l|}{$t$} & \multicolumn{2}{|c|}{$t-1$} \\
\hline & Estimate & Std. Error & Estimate & Std. Error \\
\hline Intercept & 0.002 & 0.005 & & \\
\hline Sta.Gov.Neg & 0.005 & 0.007 & 0.008 & 0.005 \\
\hline Dec.Gov.Neg & 0.002 & 0.011 & 0.013 & 0.024 \\
\hline NA.News.Neg & 0.008 & 0.008 & $0.015^{*}$ & 0.009 \\
\hline Sta.Gov.Pos & 0.002 & 0.006 & 0.005 & 0.005 \\
\hline Dec.Gov.Pos & 0.005 & 0.008 & 0.001 & 0.012 \\
\hline NA.News.Pos & 0.013 & 0.009 & 0.013 & 0.012 \\
\hline NA.Prot.Mix & 0.000 & 0.007 & -0.002 & 0.006 \\
\hline NA.Elec.Mix & -0.006 & 0.025 & 0.007 & 0.006 \\
\hline Sta.Ger.Neg & $0.008^{*}$ & 0.005 & 0.002 & 0.004 \\
\hline Sta.EU.Neg & -0.002 & 0.008 & -0.002 & 0.006 \\
\hline Int.ECB.Neg & -0.005 & 0.010 & -0.006 & 0.006 \\
\hline Sta.ECB.Neg & 0.004 & 0.009 & 0.002 & 0.007 \\
\hline Sta.Ger.Pos & -0.002 & 0.007 & 0.013 & 0.010 \\
\hline Dec.Ger.Pos & 0.006 & 0.010 & $-0.051^{*}$ & 0.030 \\
\hline Sta.EU.Pos & 0.003 & 0.012 & $-0.017^{*}$ & 0.009 \\
\hline Dec.EU.Pos & -0.029 & 0.028 & -0.017 & 0.031 \\
\hline Int.ECB.Pos & $0.061^{* * *}$ & 0.019 & -0.083 & 0.069 \\
\hline Sta.ECB.Pos & -0.004 & 0.005 & $-0.026^{* * *}$ & 0.006 \\
\hline Dec.ECB.Pos & -0.037 & 0.025 & -0.072 & 0.072 \\
\hline Sta.Ger.Mix & -0.004 & 0.006 & 0.004 & 0.006 \\
\hline Sta.EU.Mix & -0.006 & 0.008 & 0.000 & 0.006 \\
\hline Dec.EU.Mix & -0.012 & 0.016 & 0.006 & 0.013 \\
\hline Sta.ECB.Mix & 0.039 & 0.042 & -0.002 & 0.012 \\
\hline 2009.Q2 & -0.008 & 0.006 & & \\
\hline 2009.Q3 & -0.006 & 0.007 & & \\
\hline 2009.Q4 & 0.005 & 0.007 & & \\
\hline 2010.Q1 & -0.002 & 0.009 & & \\
\hline 2010.Q2 & $0.018^{*}$ & 0.009 & & \\
\hline 2010.Q3 & -0.003 & 0.005 & & \\
\hline 2010.Q4 & 0.000 & 0.006 & & \\
\hline 2011.Q1 & -0.002 & 0.006 & & \\
\hline 2011.Q2 & -0.001 & 0.006 & & \\
\hline 2011.Q3 & 0.005 & 0.007 & & \\
\hline 2011.Q4 & 0.007 & 0.007 & & \\
\hline 2012.Q1 & -0.013 & 0.017 & & \\
\hline 2012.Q2 & -0.001 & 0.006 & & \\
\hline 2012.Q3 & -0.008 & 0.007 & & \\
\hline 2012.Q4 & -0.010 & 0.007 & & \\
\hline$y_{t-1}$ & 0.102 & 0.065 & & \\
\hline$y_{t-2}$ & -0.012 & 0.041 & & \\
\hline$y_{t-3}$ & $-0.135^{*}$ & 0.082 & & \\
\hline $\begin{array}{l}\text { Note: }{ }^{*} p< \\
\text { The events hav } \\
\text { The first quar } \\
\text { column, event } \\
\text { The standard } \\
\text { covariance mat }\end{array}$ & $\begin{array}{l}* * p<0.05 \\
\text { s }[0,1] \text { repres } \\
\text { f } 2009 \text { is bas } \\
\text { denoted: Fo } \\
\text { s are based }\end{array}$ & $\begin{array}{l}* * * \quad p<0 \\
\text { ated in colu } \\
\text { category for } \\
\text { n.Actor.Dir } \\
\text { a generall. }\end{array}$ & $\begin{array}{l}R^{2}=0.104 \\
2-3, \text { and } 4-5, \\
\text { fixed effects. } \\
n, \text { cf. Table } \\
\text { eroskedastici }\end{array}$ & $\begin{array}{l}N=1037 . \\
\text { espectively. } \\
\text { In the first } \\
\text { S1 and S2. } \\
\text { consistent }\end{array}$ \\
\hline
\end{tabular}


Table S14: AR(3)DL Estimates for Italy (Model 10)

\begin{tabular}{|c|c|c|c|c|}
\hline & \multicolumn{2}{|l|}{$t$} & \multicolumn{2}{|c|}{$t-1$} \\
\hline & Estimate & Std. Error & Estimate & Std. Error \\
\hline Intercept & 0.001 & 0.006 & & \\
\hline Sta.Gov.Neg & 0.002 & 0.019 & -0.020 & 0.019 \\
\hline Dec.Gov.Neg & 0.013 & 0.009 & 0.017 & 0.029 \\
\hline NA.News.Neg & 0.007 & 0.005 & -0.006 & 0.006 \\
\hline Sta.Gov.Pos & $-0.019^{* * *}$ & 0.007 & -0.011 & 0.011 \\
\hline Dec.Gov.Pos & $-0.022^{*}$ & 0.012 & -0.017 & 0.012 \\
\hline NA.News.Pos & -0.006 & 0.006 & 0.002 & 0.007 \\
\hline NA.Prot.Mix & 0.010 & 0.009 & -0.009 & 0.008 \\
\hline NA.Elec.Mix & 0.009 & 0.011 & 0.005 & 0.025 \\
\hline Sta.Ger.Neg & $0.007^{*}$ & 0.004 & -0.000 & 0.004 \\
\hline Sta.EU.Neg & $-0.012^{* *}$ & 0.006 & $-0.038^{* *}$ & 0.015 \\
\hline Int.ECB.Neg & 0.002 & 0.006 & -0.016 & 0.017 \\
\hline Sta.ECB.Neg & $0.034^{* * *}$ & 0.009 & $-0.012^{*}$ & 0.007 \\
\hline Sta.Ger.Pos & 0.000 & 0.007 & -0.017 & 0.013 \\
\hline Dec.Ger.Pos & -0.008 & 0.011 & -0.021 & 0.018 \\
\hline Sta.EU.Pos & -0.001 & 0.009 & 0.005 & 0.022 \\
\hline Dec.EU.Pos & $-0.042^{* *}$ & 0.017 & -0.006 & 0.018 \\
\hline Int.ECB.Pos & 0.029 & 0.020 & $-0.066^{*}$ & 0.039 \\
\hline Sta.ECB.Pos & $-0.064^{* * *}$ & 0.012 & $-0.050^{* * *}$ & 0.009 \\
\hline Dec.ECB.Pos & -0.005 & 0.015 & 0.002 & 0.012 \\
\hline Sta.Ger.Mix & -0.008 & 0.006 & 0.004 & 0.005 \\
\hline Sta.EU.Mix & $-0.020^{* *}$ & 0.010 & -0.001 & 0.010 \\
\hline Dec.EU.Mix & -0.000 & 0.015 & $0.025^{* * *}$ & 0.006 \\
\hline Sta.ECB.Mix & 0.008 & 0.060 & -0.045 & 0.037 \\
\hline 2009.Q2 & -0.007 & 0.008 & & \\
\hline 2009.Q3 & -0.004 & 0.008 & & \\
\hline 2009.Q4 & -0.005 & 0.007 & & \\
\hline 2010.Q1 & 0.003 & 0.008 & & \\
\hline 2010.Q2 & 0.015 & 0.009 & & \\
\hline 2010.Q3 & 0.001 & 0.007 & & \\
\hline 2010.Q4 & 0.001 & 0.007 & & \\
\hline 2011.Q1 & -0.003 & 0.008 & & \\
\hline 2011.Q2 & 0.003 & 0.007 & & \\
\hline 2011.Q3 & 0.015 & 0.010 & & \\
\hline 2011.Q4 & 0.010 & 0.008 & & \\
\hline 2012.Q1 & -0.005 & 0.008 & & \\
\hline 2012.Q2 & 0.006 & 0.007 & & \\
\hline 2012.Q3 & 0.003 & 0.008 & & \\
\hline 2012.Q4 & 0.002 & 0.007 & & \\
\hline$y_{t-1}$ & $0.200^{* * *}$ & 0.041 & & \\
\hline$y_{t-2}$ & $-0.125^{* * *}$ & 0.044 & & \\
\hline$y_{t-3}$ & -0.024 & 0.034 & & \\
\hline $\begin{array}{l}\text { Note: }{ }^{*} p< \\
\text { The events hav } \\
\text { The first quar } \\
\text { column, event } \\
\text { The standard } \\
\text { covariance mat }\end{array}$ & $\begin{array}{l}* * p<0.05 \\
\text { ss }[0,1] \text { repres } \\
\text { f } 2009 \text { is bas } \\
\text { denoted: Fo } \\
\text { s are based }\end{array}$ & $\begin{array}{l}* * * \quad p<0 \\
\text { ated in colu } \\
\text { category for } \\
\text { n.Actor.Dir } \\
\text { a generall. }\end{array}$ & $\begin{array}{l}R^{2}=0.100 \\
2-3, \text { and } 4-5, \\
\text { fixed effects. } \\
\text { n, cf. Table } \\
\text { eroskedastici }\end{array}$ & $\begin{array}{l}N=1037 . \\
\text { espectively. } \\
\text { In the first } \\
\text { S1 and S2. } \\
\text { consistent }\end{array}$ \\
\hline
\end{tabular}


Table S15: AR(3)DL Estimates for Ireland (Model 11)

\begin{tabular}{|c|c|c|c|c|}
\hline & \multicolumn{2}{|l|}{$t$} & \multicolumn{2}{|c|}{$t-1$} \\
\hline & Estimate & Std. Error & Estimate & Std. Error \\
\hline Intercept & $0.009^{*}$ & 0.005 & & \\
\hline Sta.Gov.Neg & 0.008 & 0.006 & $0.009^{* *}$ & 0.004 \\
\hline NA.News.Neg & -0.005 & 0.004 & -0.002 & 0.004 \\
\hline Sta.Gov.Pos & 0.007 & 0.007 & 0.009 & 0.011 \\
\hline Dec.Gov.Pos & $0.016^{* *}$ & 0.008 & -0.008 & 0.008 \\
\hline NA.News.Pos & 0.004 & 0.005 & -0.005 & 0.005 \\
\hline NA.Prot.Mix & -0.017 & 0.014 & 0.043 & 0.037 \\
\hline NA.Elec.Mix & $-0.035^{* * *}$ & 0.008 & 0.011 & 0.010 \\
\hline Sta.Ger.Neg & 0.003 & 0.003 & 0.004 & 0.003 \\
\hline Sta.EU.Neg & 0.003 & 0.007 & $-0.011^{* * *}$ & 0.004 \\
\hline Int.ECB.Neg & -0.016 & 0.011 & $0.011^{*}$ & 0.007 \\
\hline Sta.ECB.Neg & $0.014^{* * *}$ & 0.004 & 0.003 & 0.009 \\
\hline Sta.Ger.Pos & 0.004 & 0.005 & -0.007 & 0.006 \\
\hline Dec.Ger.Pos & $-0.020^{*}$ & 0.012 & -0.024 & 0.024 \\
\hline Sta.EU.Pos & -0.006 & 0.007 & 0.010 & 0.014 \\
\hline Dec.EU.Pos & -0.038 & 0.024 & -0.021 & 0.023 \\
\hline Int.ECB.Pos & -0.001 & 0.016 & -0.068 & 0.053 \\
\hline Sta.ECB.Pos & $-0.028^{* * *}$ & 0.010 & $-0.023^{* * *}$ & 0.005 \\
\hline Dec.ECB.Pos & -0.030 & 0.018 & 0.013 & 0.010 \\
\hline Sta.Ger.Mix & -0.002 & 0.004 & 0.006 & 0.004 \\
\hline Sta.EU.Mix & $-0.009^{*}$ & 0.005 & 0.011 & 0.008 \\
\hline Dec.EU.Mix & -0.002 & 0.010 & -0.003 & 0.006 \\
\hline Sta.ECB.Mix & 0.000 & 0.019 & $-0.021^{* *}$ & 0.008 \\
\hline 2009.Q2 & -0.009 & 0.006 & & \\
\hline 2009.Q3 & $-0.014^{* *}$ & 0.006 & & \\
\hline 2009.Q4 & -0.010 & 0.007 & & \\
\hline 2010.Q1 & -0.010 & 0.007 & & \\
\hline 2010.Q2 & 0.006 & 0.008 & & \\
\hline 2010.Q3 & -0.005 & 0.007 & & \\
\hline 2010.Q4 & -0.007 & 0.007 & & \\
\hline 2011.Q1 & -0.008 & 0.006 & & \\
\hline 2011.Q2 & -0.007 & 0.006 & & \\
\hline 2011.Q3 & $-0.013^{*}$ & 0.007 & & \\
\hline 2011.Q4 & -0.006 & 0.006 & & \\
\hline 2012.Q1 & $-0.012^{* *}$ & 0.006 & & \\
\hline 2012.Q2 & $-0.010^{*}$ & 0.006 & & \\
\hline 2012.Q3 & -0.009 & 0.006 & & \\
\hline 2012.Q4 & -0.007 & 0.006 & & \\
\hline$y_{t-1}$ & $0.244^{* * *}$ & 0.048 & & \\
\hline$y_{t-2}$ & -0.003 & 0.036 & & \\
\hline$y_{t-3}$ & -0.036 & 0.041 & & \\
\hline $\begin{array}{l}\text { Note: }{ }^{*} p< \\
\text { The events hav } \\
\text { The first quart } \\
\text { column, events } \\
\text { The standard } \\
\text { covariance mat }\end{array}$ & $\begin{array}{l}\text { k* } p<0.05 \\
\mathrm{~s}[0,1] \text { repres } \\
2009 \text { is bas } \\
\text { denoted: Fo } \\
\text { are based }\end{array}$ & $\begin{array}{l}* * * p<0 \\
\text { ated in colu } \\
\text { category for } \\
\text { n.Actor.Dir } \\
\text { a generally }\end{array}$ & $\begin{array}{l}R^{2}=0.139 ; \\
2-3, \text { and } 4-5, \\
\text { fixed effects. } \\
n \text {, cf. Tables } \\
\text { eroskedastici }\end{array}$ & $\begin{array}{l}N=1037 . \\
\text { espectively. } \\
\text { In the first } \\
\mathrm{S} 1 \text { and } \mathrm{S} 2 . \\
\text { consistent }\end{array}$ \\
\hline
\end{tabular}


Table S16: AR(3)DL Estimates for Portugal (Model 12)

\begin{tabular}{|c|c|c|c|c|}
\hline & \multicolumn{2}{|l|}{$t$} & \multicolumn{2}{|c|}{$t-1$} \\
\hline & Estimate & Std. Error & Estimate & Std. Error \\
\hline Intercept & 0.005 & 0.006 & & \\
\hline Sta.Gov.Neg & -0.007 & 0.010 & -0.003 & 0.016 \\
\hline Dec.Gov.Neg & 0.005 & 0.018 & $0.021^{*}$ & 0.011 \\
\hline NA.News.Neg & $0.016^{* *}$ & 0.007 & 0.011 & 0.007 \\
\hline Sta.Gov.Pos & -0.006 & 0.008 & 0.008 & 0.010 \\
\hline Dec.Gov.Pos & $-0.031^{*}$ & 0.018 & -0.000 & 0.015 \\
\hline NA.News.Pos & 0.011 & 0.009 & -0.001 & 0.006 \\
\hline NA.Prot.Mix & $0.015^{* *}$ & 0.007 & 0.008 & 0.014 \\
\hline NA.Elec.Mix & 0.011 & 0.013 & $0.023^{*}$ & 0.013 \\
\hline Sta.Ger.Neg & 0.006 & 0.004 & -0.001 & 0.003 \\
\hline Sta.EU.Neg & $0.014^{* *}$ & 0.006 & -0.001 & 0.005 \\
\hline Int.ECB.Neg & -0.025 & 0.018 & 0.005 & 0.007 \\
\hline Sta.ECB.Neg & 0.008 & 0.008 & 0.003 & 0.008 \\
\hline Sta.Ger.Pos & 0.006 & 0.009 & -0.012 & 0.008 \\
\hline Dec.Ger.Pos & -0.005 & 0.008 & -0.041 & 0.028 \\
\hline Sta.EU.Pos & $-0.020^{* *}$ & 0.010 & -0.010 & 0.016 \\
\hline Dec.EU.Pos & -0.034 & 0.024 & -0.024 & 0.026 \\
\hline Int.ECB.Pos & $0.049^{* *}$ & 0.025 & -0.096 & 0.063 \\
\hline Sta.ECB.Pos & $-0.037^{* * *}$ & 0.013 & $-0.030^{* *}$ & 0.014 \\
\hline Dec.ECB.Pos & -0.024 & 0.022 & 0.017 & 0.013 \\
\hline Sta.Ger.Mix & -0.002 & 0.005 & 0.007 & 0.006 \\
\hline Sta.EU.Mix & -0.003 & 0.014 & 0.016 & 0.015 \\
\hline Dec.EU.Mix & -0.009 & 0.011 & -0.008 & 0.008 \\
\hline Sta.ECB.Mix & 0.005 & 0.010 & $-0.015^{* *}$ & 0.007 \\
\hline 2009.Q2 & -0.008 & 0.008 & & \\
\hline 2009.Q3 & -0.011 & 0.008 & & \\
\hline 2009.Q4 & -0.006 & 0.008 & & \\
\hline 2010.Q1 & -0.000 & 0.010 & & \\
\hline 2010.Q2 & 0.012 & 0.009 & & \\
\hline 2010.Q3 & -0.002 & 0.007 & & \\
\hline 2010.Q4 & -0.007 & 0.008 & & \\
\hline 2011.Q1 & -0.007 & 0.008 & & \\
\hline 2011.Q2 & -0.002 & 0.008 & & \\
\hline 2011.Q3 & -0.003 & 0.007 & & \\
\hline 2011.Q4 & -0.003 & 0.007 & & \\
\hline 2012.Q1 & -0.009 & 0.007 & & \\
\hline 2012.Q2 & -0.006 & 0.007 & & \\
\hline 2012.Q3 & -0.004 & 0.007 & & \\
\hline 2012.Q4 & -0.004 & 0.007 & & \\
\hline$y_{t-1}$ & $0.289^{* * *}$ & 0.042 & & \\
\hline$y_{t-2}$ & $-0.089^{*}$ & 0.048 & & \\
\hline$y_{t-3}$ & -0.038 & 0.038 & & \\
\hline $\begin{array}{l}\text { Note: }{ }^{*} p<0 \text {. } \\
\text { events have la } \\
\text { The first quart } \\
\text { column, events } \\
\text { The standard } \\
\text { covariance mat }\end{array}$ & $\begin{array}{l}p<0.05, \\
1] \text { represent } \\
2009 \text { is base } \\
\text { denoted: For } \\
\text { are based or }\end{array}$ & $\begin{array}{l}p<0.01 ; 1 \\
\text { in column } \\
\text { ategory for } \\
\text { 1.Actor.Dire } \\
\text { a generally }\end{array}$ & $\begin{array}{l}=0.158 ; N \\
3, \text { and } 4-5 \text {, } \\
\text { fixed effects } \\
\text { n, cf. Table } \\
\text { roskedastici }\end{array}$ & $\begin{array}{l}\text { 1037. The } \\
\text { espectively. } \\
\text { In the first } \\
\text { S1 and S2. } \\
\text { consistent }\end{array}$ \\
\hline
\end{tabular}


Table S17: AR(3)DL Estimates for Spain (Model 13)

\begin{tabular}{|c|c|c|c|c|}
\hline & \multicolumn{2}{|l|}{$t$} & \multicolumn{2}{|c|}{$t-1$} \\
\hline & Estimate & Std. Error & Estimate & Std. Error \\
\hline Intercept & 0.000 & 0.005 & & \\
\hline Sta.Gov.Neg & 0.006 & 0.018 & -0.005 & 0.010 \\
\hline Dec.Gov.Neg & 0.005 & 0.010 & 0.008 & 0.014 \\
\hline NA.News.Neg & 0.005 & 0.004 & -0.000 & 0.004 \\
\hline Sta.Gov.Pos & 0.001 & 0.008 & 0.008 & 0.007 \\
\hline Dec.Gov.Pos & -0.002 & 0.008 & -0.009 & 0.008 \\
\hline NA.News.Pos & $-0.014^{*}$ & 0.008 & $-0.016^{* *}$ & 0.007 \\
\hline NA.Prot.Mix & 0.014 & 0.009 & -0.002 & 0.011 \\
\hline NA.Elec.Mix & 0.015 & 0.012 & 0.007 & 0.012 \\
\hline Sta.Ger.Neg & 0.005 & 0.004 & 0.001 & 0.003 \\
\hline Sta.EU.Neg & 0.014 & 0.013 & $-0.030^{* *}$ & 0.013 \\
\hline Int.ECB.Neg & 0.008 & 0.015 & -0.008 & 0.013 \\
\hline Sta.ECB.Neg & $0.042^{* * *}$ & 0.009 & -0.014 & 0.013 \\
\hline Sta.Ger.Pos & -0.003 & 0.008 & -0.016 & 0.010 \\
\hline Dec.Ger.Pos & -0.007 & 0.011 & -0.022 & 0.024 \\
\hline Sta.EU.Pos & -0.001 & 0.014 & -0.000 & 0.027 \\
\hline Dec.EU.Pos & $-0.050^{* *}$ & 0.022 & -0.010 & 0.023 \\
\hline Int.ECB.Pos & 0.019 & 0.035 & -0.050 & 0.049 \\
\hline Sta.ECB.Pos & $-0.056^{* *}$ & 0.024 & $-0.046^{* * *}$ & 0.011 \\
\hline Dec.ECB.Pos & -0.009 & 0.018 & 0.020 & 0.014 \\
\hline Sta.Ger.Mix & -0.006 & 0.006 & 0.006 & 0.005 \\
\hline Sta.EU.Mix & $-0.017^{*}$ & 0.009 & -0.003 & 0.010 \\
\hline Dec.EU.Mix & 0.002 & 0.016 & $0.022^{* * *}$ & 0.007 \\
\hline Sta.ECB.Mix & -0.014 & 0.065 & $-0.028^{* * *}$ & 0.008 \\
\hline 2009.Q2 & -0.003 & 0.009 & & \\
\hline 2009.Q3 & -0.004 & 0.008 & & \\
\hline 2009.Q4 & 0.000 & 0.008 & & \\
\hline 2010.Q1 & 0.003 & 0.008 & & \\
\hline 2010.Q2 & $0.021^{* *}$ & 0.009 & & \\
\hline 2010.Q3 & -0.000 & 0.007 & & \\
\hline 2010.Q4 & 0.005 & 0.007 & & \\
\hline 2011.Q1 & -0.002 & 0.007 & & \\
\hline 2011.Q2 & 0.004 & 0.007 & & \\
\hline 2011.Q3 & 0.004 & 0.009 & & \\
\hline 2011.Q4 & 0.002 & 0.008 & & \\
\hline 2012.Q1 & -0.002 & 0.007 & & \\
\hline 2012.Q2 & 0.005 & 0.007 & & \\
\hline 2012.Q3 & 0.005 & 0.007 & & \\
\hline 2012.Q4 & 0.003 & 0.007 & & \\
\hline$y_{t-1}$ & $0.226^{* * *}$ & 0.041 & & \\
\hline$y_{t-2}$ & $-0.105^{* *}$ & 0.042 & & \\
\hline$y_{t-3}$ & $-0.094^{* * *}$ & 0.034 & & \\
\hline $\begin{array}{l}\text { Note: }{ }^{*} p< \\
\text { The events hav } \\
\text { The first quart } \\
\text { column, events } \\
\text { The standard } \\
\text { covariance mat }\end{array}$ & $\begin{array}{l}* * p<0.05 \\
\text { s }[0,1] \text { repres } \\
2009 \text { is base } \\
\text { denoted: Fo } \\
\text { s are based }\end{array}$ & $\begin{array}{l}\text { *** } p<0 \\
\text { nted in colu } \\
\text { category for } \\
\text { m.Actor.Dir } \\
\text { a generall }\end{array}$ & $\begin{array}{l}R^{2}=0.106 \\
2-3, \text { and } 4-5, \\
\text { fixed effects. } \\
\text { n, cf. Tables } \\
\text { eroskedastici }\end{array}$ & $\begin{array}{l}N=1037 . \\
\text { espectively. } \\
\text { In the first } \\
\mathrm{S} 1 \text { and } \mathrm{S} 2 . \\
\text { consistent }\end{array}$ \\
\hline
\end{tabular}


Table S18: AR(3)DL-GARCH(1,1) Estimates for Greece (Model 14)

\begin{tabular}{|c|c|c|c|c|}
\hline & \multicolumn{2}{|l|}{$t$} & \multicolumn{2}{|c|}{$t-1$} \\
\hline & Estimate & Std. Error & Estimate & Std. Error \\
\hline \multicolumn{5}{|c|}{ Conditional mean equation: } \\
\hline Intercept & -0.005 & 0.015 & & \\
\hline Sta.Gov.Neg & -0.002 & 0.004 & -0.003 & 0.003 \\
\hline Dec.Gov.Neg & 0.005 & 0.018 & 0.031 & 0.044 \\
\hline NA.News.Neg & 0.004 & 0.005 & 0.008 & 0.006 \\
\hline Sta.Gov.Pos & -0.004 & 0.005 & 0.002 & 0.004 \\
\hline Dec.Gov.Pos & 0.005 & 0.011 & 0.001 & 0.006 \\
\hline NA.News.Pos & -0.002 & 0.008 & 0.009 & 0.011 \\
\hline NA.Prot.Mix & 0.004 & 0.005 & -0.002 & 0.009 \\
\hline NA.Elec.Mix & 0.013 & 0.040 & 0.020 & 0.020 \\
\hline Sta.Ger.Neg & 0.003 & 0.003 & 0.003 & 0.002 \\
\hline Sta.EU.Neg & 0.007 & 0.010 & 0.004 & 0.004 \\
\hline Int.ECB.Neg & 0.005 & 0.004 & 0.004 & 0.006 \\
\hline Sta.ECB.Neg & 0.015 & 0.009 & 0.011 & 0.009 \\
\hline Sta.Ger.Pos & -0.003 & 0.004 & 0.005 & 0.007 \\
\hline Dec.Ger.Pos & $-0.022^{* * *}$ & 0.006 & $-0.040^{* * *}$ & 0.014 \\
\hline Sta.EU.Pos & -0.003 & 0.014 & -0.005 & 0.018 \\
\hline Dec.EU.Pos & $-0.011^{* *}$ & 0.005 & -0.007 & 0.011 \\
\hline Int.ECB.Pos & 0.005 & 0.014 & 0.015 & 0.017 \\
\hline Sta.ECB.Pos & 0.003 & 0.006 & $-0.018^{* *}$ & 0.008 \\
\hline Dec.ECB.Pos & $0.017^{* *}$ & 0.008 & -0.001 & 0.004 \\
\hline Sta.Ger.Mix & 0.003 & 0.003 & 0.002 & 0.004 \\
\hline Sta.EU.Mix & -0.011 & 0.008 & -0.008 & 0.009 \\
\hline Dec.EU.Mix & $-0.010^{* *}$ & 0.004 & 0.008 & 0.010 \\
\hline Sta.ECB.Mix & 0.004 & 0.007 & -0.004 & 0.013 \\
\hline 2009.Q2 & 0.006 & 0.016 & & \\
\hline 2009.Q3 & -0.007 & 0.016 & & \\
\hline 2009.Q4 & 0.007 & 0.015 & & \\
\hline 2010.Q1 & 0.007 & 0.018 & & \\
\hline 2010.Q2 & 0.012 & 0.017 & & \\
\hline 2010.Q3 & 0.006 & 0.015 & & \\
\hline 2010.Q4 & 0.005 & 0.016 & & \\
\hline 2011.Q1 & 0.007 & 0.015 & & \\
\hline 2011.Q2 & 0.004 & 0.016 & & \\
\hline 2011.Q3 & 0.012 & 0.016 & & \\
\hline 2011.Q4 & 0.007 & 0.015 & & \\
\hline 2012.Q1 & 0.010 & 0.017 & & \\
\hline 2012.Q2 & 0.001 & 0.017 & & \\
\hline 2012.Q3 & -0.001 & 0.015 & & \\
\hline 2012.Q4 & -0.006 & 0.016 & & \\
\hline$y_{t-1}$ & $0.316^{* * *}$ & 0.070 & & \\
\hline$y_{t-2}$ & -0.024 & 0.068 & & \\
\hline$y_{t-3}$ & -0.032 & 0.052 & & \\
\hline \multicolumn{5}{|c|}{ Conditional variance equation: } \\
\hline Intercept & 0.000 & 0.000 & & \\
\hline$\varepsilon_{t-1}^{2}$ & $0.483^{* * *}$ & 0.110 & & \\
\hline$\sigma_{t-1}^{2}$ & $0.516^{* * *}$ & 0.104 & & \\
\hline
\end{tabular}

Note: ${ }^{*} p<0.1,{ }^{* *} p<0.05,{ }^{* * *} p<0.01 ; N=1037$. The events have lags [0,1] represented in columns 2-3, and 4-5, respectively. The first quarter of 2009 is base category for the fixed effects. In the first column, events are denoted: Form.Actor.Direction, cf. Tables $\mathrm{S} 1$ and $\mathrm{S} 2$. 
Table S19: AR(3)DL-GARCH(1,1) Estimates for Italy (Model 15)

\begin{tabular}{|c|c|c|c|c|}
\hline & \multicolumn{2}{|l|}{$t$} & \multicolumn{2}{|c|}{$t-1$} \\
\hline & Estimate & Std. Error & Estimate & Std. Error \\
\hline Conditional mean equation: & & & & \\
\hline Intercept & 0.007 & 0.006 & & \\
\hline Sta.Gov.Neg & 0.014 & 0.030 & -0.010 & 0.014 \\
\hline Dec.Gov.Neg & $0.027^{* * *}$ & 0.009 & $0.027^{*}$ & 0.015 \\
\hline NA.News.Neg & $0.011^{* * *}$ & 0.004 & -0.002 & 0.005 \\
\hline Sta.Gov.Pos & -0.002 & 0.009 & -0.005 & 0.007 \\
\hline Dec.Gov.Pos & $-0.021^{* *}$ & 0.010 & -0.012 & 0.009 \\
\hline NA.News.Pos & -0.001 & 0.006 & -0.003 & 0.007 \\
\hline NA.Prot.Mix & 0.012 & 0.008 & -0.008 & 0.009 \\
\hline NA.Elec.Mix & 0.011 & 0.014 & 0.003 & 0.020 \\
\hline Sta.Ger.Neg & 0.005 & 0.004 & 0.001 & 0.003 \\
\hline Sta.EU.Neg & -0.003 & 0.006 & $-0.044^{* *}$ & 0.022 \\
\hline Int.ECB.Neg & 0.007 & 0.006 & -0.011 & 0.011 \\
\hline Sta.ECB.Neg & $0.034^{* * *}$ & 0.009 & -0.007 & 0.010 \\
\hline Sta.Ger.Pos & -0.001 & 0.006 & 0.001 & 0.009 \\
\hline Dec.Ger.Pos & $-0.023^{*}$ & 0.012 & 0.004 & 0.012 \\
\hline Sta.EU.Pos & 0.001 & 0.015 & -0.004 & 0.022 \\
\hline Dec.EU.Pos & -0.018 & 0.014 & -0.010 & 0.012 \\
\hline Int.ECB.Pos & 0.008 & 0.029 & -0.032 & 0.026 \\
\hline Sta.ECB.Pos & $-0.056^{* * *}$ & 0.011 & $-0.060^{* * *}$ & 0.011 \\
\hline Dec.ECB.Pos & 0.015 & 0.009 & 0.007 & 0.007 \\
\hline Sta.Ger.Mix & -0.008 & 0.005 & 0.001 & 0.006 \\
\hline Sta.EU.Mix & $-0.016^{* *}$ & 0.008 & 0.006 & 0.006 \\
\hline Dec.EU.Mix & 0.003 & 0.010 & $0.015^{* *}$ & 0.007 \\
\hline Sta.ECB.Mix & 0.036 & 0.055 & $-0.084^{* * *}$ & 0.011 \\
\hline 2009.Q2 & -0.010 & 0.007 & & \\
\hline 2009.Q3 & -0.008 & 0.010 & & \\
\hline 2009.Q4 & -0.012 & 0.008 & & \\
\hline 2010.Q1 & -0.003 & 0.008 & & \\
\hline 2010.Q2 & -0.001 & 0.010 & & \\
\hline 2010.Q3 & -0.004 & 0.008 & & \\
\hline 2010.Q4 & -0.007 & 0.009 & & \\
\hline 2011.Q1 & -0.010 & 0.007 & & \\
\hline 2011.Q2 & -0.005 & 0.008 & & \\
\hline 2011.Q3 & -0.001 & 0.009 & & \\
\hline 2011.Q4 & -0.002 & 0.008 & & \\
\hline 2012.Q1 & -0.010 & 0.009 & & \\
\hline 2012.Q2 & -0.001 & 0.008 & & \\
\hline 2012.Q3 & -0.006 & 0.008 & & \\
\hline 2012.Q4 & -0.007 & 0.007 & & \\
\hline$y_{t-1}$ & $0.233^{* * *}$ & 0.038 & & \\
\hline$y_{t-2}$ & $-0.170^{* * *}$ & 0.038 & & \\
\hline$y_{t-3}$ & 0.006 & 0.038 & & \\
\hline Conditional variance equation: & & & & \\
\hline Intercept & $0.000^{* *}$ & 0.000 & & \\
\hline$\varepsilon_{t-1}^{2}$ & $0.275^{* * *}$ & 0.081 & & \\
\hline$\sigma_{t-1}^{2}$ & $0.597^{* * *}$ & 0.120 & & \\
\hline
\end{tabular}

Note: ${ }^{*} p<0.1,{ }^{* *} p<0.05,{ }^{* * *} p<0.01 ; N=1037$. The events have lags [0,1] represented in columns 2-3, and 4-5, respectively. The first quarter of 2009 is base category for the fixed effects. In the first column, events are denoted: Form.Actor.Direction, cf. Tables $\mathrm{S} 1$ and $\mathrm{S} 2$. 
Table S20: AR(3)DL-GARCH(1,1) Estimates for Ireland (Model 16)

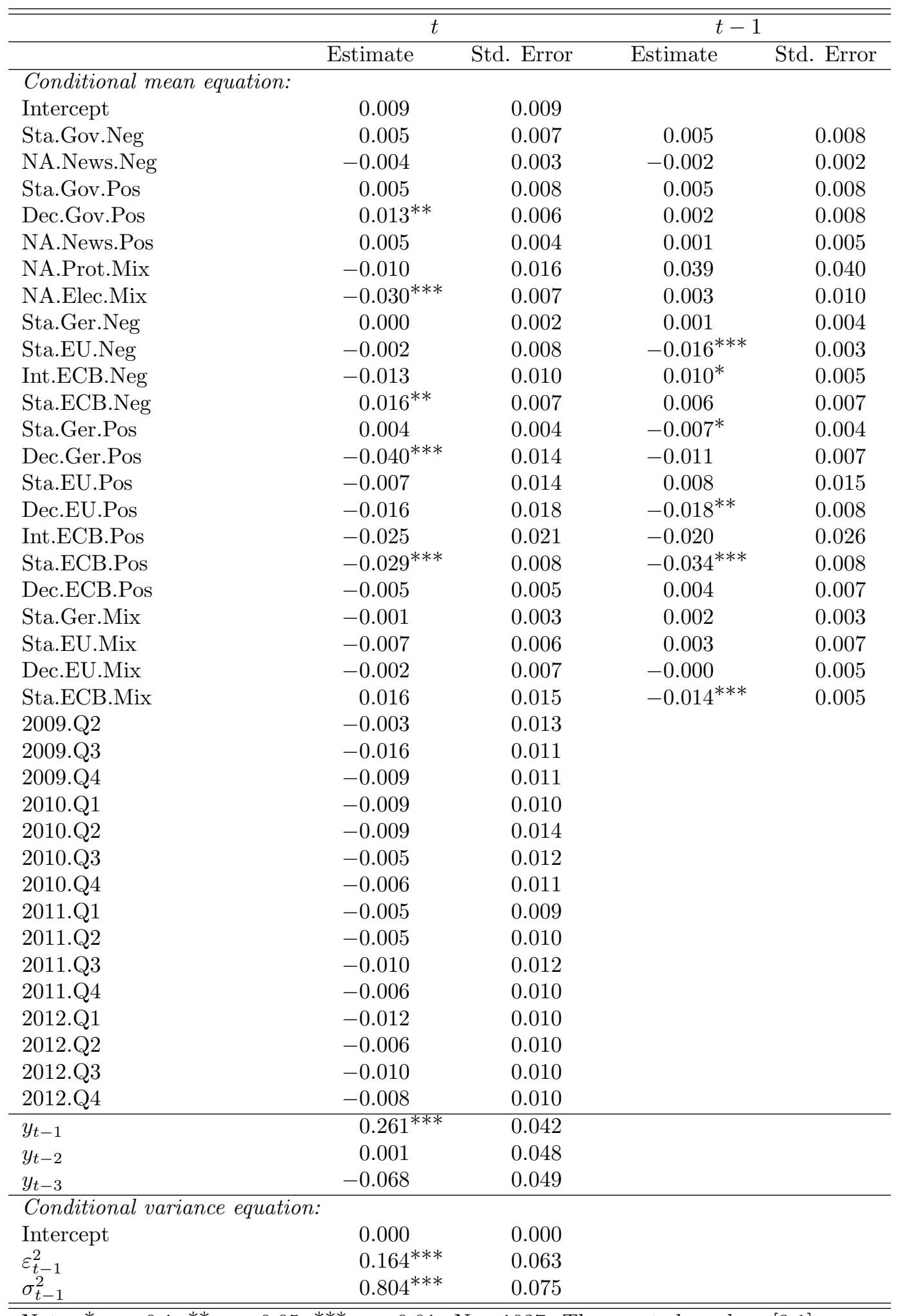

Note: ${ }^{*} p<0.1,{ }^{* *} p<0.05,{ }^{* * *} p<0.01 ; N=1037$. The events have lags [0,1] represented in columns 2-3, and 4-5, respectively. The first quarter of 2009 is base category for the fixed effects. In the first column, events are denoted: Form.Actor.Direction, cf. Tables S1 and S2. 
Table S21: AR(3)DL-GARCH(1,1) Estimates for Portugal (Model 17)

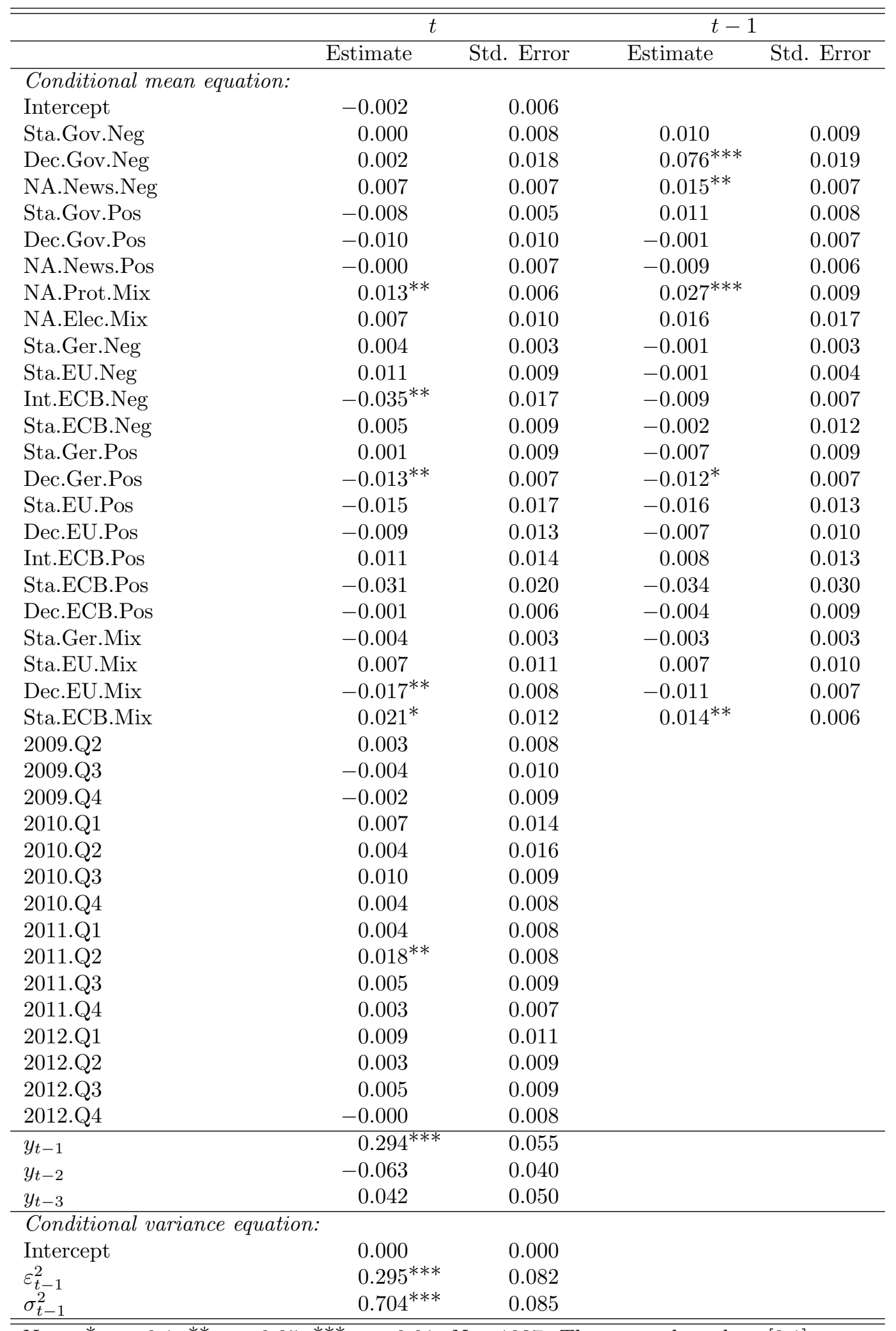

Note: ${ }^{*} p<0.1,{ }^{* *} p<0.05,{ }^{* * *} p<0.01 ; N=1037$. The events have lags [0,1] represented in columns 2-3, and 4-5, respectively. The first quarter of 2009 is base category for the fixed effects. In the first column, events are denoted: Form.Actor.Direction, cf. Tables $\mathrm{S} 1$ and $\mathrm{S} 2$. 
Table S22: AR(3)DL-GARCH(1,1) Estimates for Spain (Model 18)

\begin{tabular}{|c|c|c|c|c|}
\hline & \multicolumn{2}{|l|}{$t$} & \multicolumn{2}{|c|}{$t-1$} \\
\hline & Estimate & Std. Error & Estimate & Std. Error \\
\hline Conditional mean equation: & & & & \\
\hline Intercept & $-0.014^{* *}$ & 0.007 & & \\
\hline Sta.Gov.Neg & 0.009 & 0.022 & -0.007 & 0.015 \\
\hline Dec.Gov.Neg & 0.002 & 0.009 & 0.008 & 0.011 \\
\hline NA.News.Neg & 0.003 & 0.004 & -0.001 & 0.004 \\
\hline Sta.Gov.Pos & 0.001 & 0.006 & 0.009 & 0.007 \\
\hline Dec.Gov.Pos & -0.001 & 0.007 & 0.000 & 0.008 \\
\hline NA.News.Pos & $-0.013^{*}$ & 0.008 & $-0.013^{* *}$ & 0.005 \\
\hline NA.Prot.Mix & 0.008 & 0.011 & 0.003 & 0.008 \\
\hline NA.Elec.Mix & 0.010 & 0.014 & 0.015 & 0.012 \\
\hline Sta.Ger.Neg & 0.003 & 0.004 & -0.002 & 0.003 \\
\hline Sta.EU.Neg & 0.024 & 0.018 & $-0.035^{*}$ & 0.019 \\
\hline Int.ECB.Neg & 0.011 & 0.009 & -0.001 & 0.008 \\
\hline Sta.ECB.Neg & $0.042^{* *}$ & 0.018 & -0.006 & 0.022 \\
\hline Sta.Ger.Pos & -0.002 & 0.010 & -0.005 & 0.008 \\
\hline Dec.Ger.Pos & -0.026 & 0.018 & -0.010 & 0.017 \\
\hline Sta.EU.Pos & -0.005 & 0.013 & -0.005 & 0.021 \\
\hline Dec.EU.Pos & $-0.034^{* *}$ & 0.015 & -0.018 & 0.014 \\
\hline Int.ECB.Pos & -0.015 & 0.060 & 0.013 & 0.039 \\
\hline Sta.ECB.Pos & $-0.054^{*}$ & 0.031 & $-0.056^{* * *}$ & 0.021 \\
\hline Dec.ECB.Pos & $0.023^{*}$ & 0.014 & $0.027^{* * *}$ & 0.010 \\
\hline Sta.Ger.Mix & -0.001 & 0.006 & 0.004 & 0.006 \\
\hline Sta.EU.Mix & $-0.013^{*}$ & 0.007 & 0.005 & 0.006 \\
\hline Dec.EU.Mix & -0.001 & 0.012 & 0.011 & 0.008 \\
\hline Sta.ECB.Mix & 0.035 & 0.046 & -0.006 & 0.020 \\
\hline 2009.Q2 & 0.011 & 0.011 & & \\
\hline 2009.Q3 & -0.004 & 0.024 & & \\
\hline 2009.Q4 & $0.014^{*}$ & 0.008 & & \\
\hline 2010.Q1 & $0.016^{*}$ & 0.008 & & \\
\hline 2010.Q2 & $0.027^{* *}$ & 0.012 & & \\
\hline 2010.Q3 & $0.015^{*}$ & 0.008 & & \\
\hline 2010.Q4 & $0.016^{*}$ & 0.008 & & \\
\hline 2011.Q1 & 0.012 & 0.008 & & \\
\hline 2011.Q2 & $0.014^{*}$ & 0.008 & & \\
\hline 2011.Q3 & $0.022^{*}$ & 0.011 & & \\
\hline 2011.Q4 & 0.015 & 0.011 & & \\
\hline 2012.Q1 & 0.012 & 0.009 & & \\
\hline 2012.Q2 & $0.020^{* *}$ & 0.008 & & \\
\hline 2012.Q3 & $0.018^{* *}$ & 0.008 & & \\
\hline 2012.Q4 & $0.015^{*}$ & 0.008 & & \\
\hline$y_{t-1}$ & $0.248^{* * *}$ & 0.057 & & \\
\hline$y_{t-2}$ & $-0.134^{* * *}$ & 0.049 & & \\
\hline$y_{t-3}$ & -0.060 & 0.042 & & \\
\hline Conditional variance equation: & & & & \\
\hline Intercept & 0.000 & 0.000 & & \\
\hline$\varepsilon_{t-1}^{2}$ & $0.344^{* *}$ & 0.139 & & \\
\hline$\sigma_{t-1}^{2}$ & $0.553^{* *}$ & 0.228 & & \\
\hline
\end{tabular}

Note: ${ }^{*} p<0.1,{ }^{* *} p<0.05,{ }^{* * *} p<0.01 ; N=1037$. The events have lags [0,1] represented in columns 2-3, and 4-5, respectively. The first quarter of 2009 is base category for the fixed effects. In the first column, events are denoted: Form.Actor.Direction, cf. Tables $\mathrm{S} 1$ and $\mathrm{S} 2$. 


\section{References}

Bollerslev, T. (1986) 'Generalized autoregressive conditional heteroskedasticity'. Journal of econometrics, Vol. 31, No. 3, pp. 307-327.

Bølstad, J. and Elhardt, C. (2015) 'To Bail Out or Not to Bail Out? Crisis Politics, Credibility, and Default Risk in the Eurozone'. European Union Politics, Vol. 16, No. 3.

Bruegel (2014) 'Eurocrisis Timeline'. Available at <http://www.bruegel.org/blog/ eurocrisistimeline/>. Accessed 13 February 2014.

Engle, R. F. (1982) 'Autoregressive conditional heteroscedasticity with estimates of the variance of United Kingdom inflation'. Econometrica: Journal of the Econometric Society, Vol. 50, No. 4, pp. 987-1007.

Eurointelligence (2014) 'Eurozone Blog'. Available at <http://www.eurointelligence. com>. Accessed 13 February 2014.

European Commission (2014) 'Eurozone Blog'. Available at <http://ec.europa.eu/ economy_finance/crisis/2010-05_en.htm>. Accessed 13 February 2014.

Fisher, T. J. and Gallagher, C. M. (2012) 'New Weighted Portmanteau Statistics for Time series Goodness of Fit Testing'. Journal of the American Statistical Association, Vol. 107, No. 498, pp. 777-787.

King, G. and Roberts, M. E. (2014) 'How Robust Standard Errors Expose Methodological Problems They Do Not Fix, and What to Do About It'. Political Analysis, Vol. 23, No. 2, pp. 159-179.

Li, W. and Mak, T. (1994) 'On the Squared Residual Autocorrelations in Non-Linear Time Series with Conditional Heteroskedasticity'. Journal of Time Series Analysis, Vol. 15, No. 6, pp. 627-636.

Ljung, G. M. and Box, G. E. (1978) 'On a measure of lack of fit in time series models'. Biometrika, Vol. 65, No. 2, pp. 297-303.

Moody's (2013) 'Rating Methodology Sovereign Bond Ratings'. Moody's Investors Service, pp. 1-22.

Smeets, D. and Zimmermann, M. (2013) 'Did the EU Summits Succeed in Convincing the Markets during the Recent Crisis?' JCMS: Journal of Common Market Studies, Vol. 51, No. 6, pp. 1158-1177. 
Standard and Poor's (2011) 'Sovereign Government Rating Methodology And Assumptions'. Global Credit Portal, pp. 1-43.

White, H. (1980) 'A heteroskedasticity-consistent covariance matrix estimator and a direct test for heteroskedasticity'. Econometrica: Journal of the Econometric Society, Vol. 48, No. 4, pp. 817-838. 